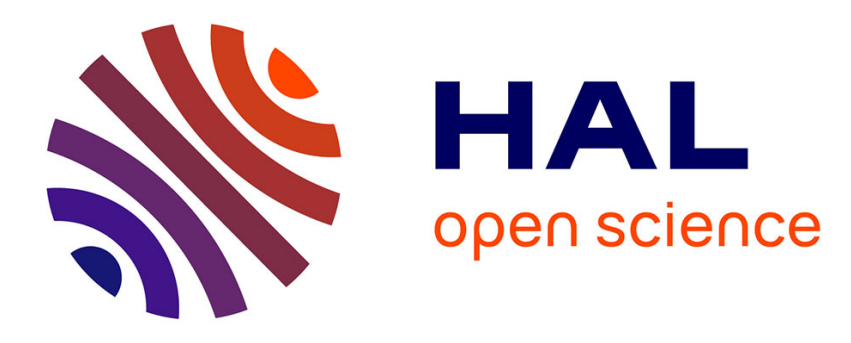

\title{
Les inscriptions du tympan de la cathédrale de Jaca
}

Robert Favreau

\section{To cite this version:}

Robert Favreau. Les inscriptions du tympan de la cathédrale de Jaca. Comptes-rendus des séances de l'Académie des inscriptions et belles-lettres, 1996, 140 (2), pp.535 -560. 10.3406/crai.1996.15603. halshs-03206285

\section{HAL Id: halshs-03206285 \\ https://shs.hal.science/halshs-03206285}

Submitted on 23 Apr 2021

HAL is a multi-disciplinary open access archive for the deposit and dissemination of scientific research documents, whether they are published or not. The documents may come from teaching and research institutions in France or abroad, or from public or private research centers.
L'archive ouverte pluridisciplinaire HAL, est destinée au dépôt et à la diffusion de documents scientifiques de niveau recherche, publiés ou non, émanant des établissements d'enseignement et de recherche français ou étrangers, des laboratoires publics ou privés. 


\section{Les inscriptions du tympan de la cathédrale de Jaca}

\section{Robert Favreau}

\section{Citer ce document / Cite this document :}

Favreau Robert. Les inscriptions du tympan de la cathédrale de Jaca. In: Comptes rendus des séances de l'Académie des Inscriptions et Belles-Lettres, $140^{\mathrm{e}}$ année, N. 2, 1996. pp. 535-560;

doi : https://doi.org/10.3406/crai.1996.15603

https://www.persee.fr/doc/crai_0065-0536_1996_num_140_2_15603

Fichier pdf généré le 21/05/2018 


\title{
COMMUNICATION
}

\author{
IES INSCRIPTIONS DU TYMPAN DE LA CATHEDDRALE DE JACA, \\ PAR M. ROBERT FAVREAI, CORRESPONIDANT DE I'ACADEMIE
}

Au début du $\mathrm{XI}^{*}$ siècle Jaca n'est encore qu'un modeste bourg, au débouché du col du Somport, dans le petit comté d'Aragon, qu'un mariage livra au royaume de Navarre. Fils du roi de Navarre Sanche le Grand (1004-1035), Ramire $\mathrm{I}^{\mathrm{rr}}$ hérite du comté de Jaca, réunit à la mort de son frère Gonzalo les comtés de Sobrarbe et de Ribagorza et prend, à partir de 1038, le titre de roi d'Aragon. Jaca devient cité épiscopale et capitale royale. Mais à la fin de 1096 Huesca est reprise aux Musulmans, et le siège épiscopal y est transféré en 1098. Jaca conservera sa juridiction diocésaine et son chapitre, tout en n'ayant plus pour évêque que celui de Huesca'. Le dernier tiers du siècle est une période forte dans l'histoire de la ville. Le rite mozarabe est abandonné en Aragon pour le rite romain, à la suite de la légation du cardinal Hugo Candidus en 1064-1065, du voyage à Rome du roi Sancho Ramírez en 1068 : ce changement a lieu en l'abbaye de San Juan de la Peña le 22 mars 1071, à San Victorian et à Loarre la même année, puis à Jaca avec l'arrivée sur le siège pontifical du frère du roi, Garcia, en 1076, pour se terminer avec San Vicente de Roda en 1092. En 1076 l'évêque de Jaca a aussi restauré la vie canoniale en son chapitre, en y introduisant la règle de saint Augustin ${ }^{2}$, ce que fait à son tour l'évêque Raimundo Dalmacio à Roda en 10923.

D'infinies discussions ont eu lieu sur les dates du chantier de construction de la cathédrale Saint-Pierre de Jaca. Dès 1924 et à nouveau en 1928 Arthur Kingsley Porter plaçait les travaux vers le milieu du XI' siècle, avec une progression suffisante pour permettre la tenue d'un concile en 1063 , date à laquelle le portail ouest était

1. René Crozet, L'art roman en Aragon et en Navarre. Conditions historiques \$, Cahiers de Civilisation médiévale V, 1962, p. 35-61 ; Serafín Moralejo Alvarez, "La sculpture romane de la cathédrale de Jaca. F́tat des questions ", Cahiers de Saint - Michel de Cuxa, ${ }^{\circ} 10$, 1979 , p. $79-80$.

2. Antonio Ubieto Arteta, \& La introducción del rito romano en Aragón y Navarra *, Príncipe de Viana 1/2, p. 299-324; Antonio Durán Gudiol, * La iglesia en Aragón durante el siglo XI *, Estudios de edad media de la corona de Aragon IV, 1951, p. 7.68.

3. Ricardo del Arco, Fundaciones monasticas en el Pirines aragonés „, Principe de Viana XIJVI-XI.VII, 1952, p. 296. 
commencé mais le tympan non encore achevé. Il pensait, de ce fait, que Jaca offrait le plus ancien tympan sculpté d'Europé. Leopoldo Torres Balbas' et Georges Gaillard' mettaient aussitôt en doute à partir d'une étude du style, cette chronologie, pour retenir l'un le dernier quart du siècle, l'autre, dans sa thèse de 1938 , les environs de 1100. Les trois documents de 1063 concile de Jaca, donations à la cathédrale ont fait l'objet en 1964 d'une sérieuse critique diplomatique qui conclut à leur faussetée, critique qu'a retenue la majorité, mais non la totalité, des auteurs qui ont par la suite écrit sur la cathédrale de Jaca. Serafín Moralejo part de deux données historiques incontestables: une donation ad laborem de doña Urraca avant 1094, la reconquête de IJuesca et le transfert du siège épiscopal dans la nouvelle capitale de l'Aragon en 1096-1098, et de la constatation d'une grande unité de style dans la construction pour retenir la dernière décennie du XI" siècle pour le tympan de la cathédrale", ce qu'admettent aujourd'hui Marcel Durliat, Willibald Sauerländer et la plupart des historiens de l'art".

Le programme iconographique du tympan de Jaca est accompagné d'une série de commentaires épigraphiques. I ee sens général ne souffre aucune ambiguité, mais l'inscription qui fait, du chrisme placé au centre du tympan, une figure trinitaire a donné lieu, à son tour, à une abondante littérature qui n'avait, jusqu’à ce jour, pas trouvé sa véritable clé. Je voudrais donc ici reprendre l'ensemble des inscriptions du tympan pour en dégager le message aussi riche et complexe qu'original (fig. 1).

Le tympan est composé d'un chrisme entouré de deux lions, ce qui se trouve dans deux autres tympans aragonais, Santa Cruz de

4. Arthur Kingsley Porter, a The Tomb of Joña Sancha and the Romanesque Art of Aragon , Burlington .Magazine XI.V, 1924, p. 165-179; Id., Spanish Romanesque Sculpture, I, Florence/Paris, 1928, p. 70.

5. La escultura románica aragonesa y el crismón de los tímpanos de las iglesias de la región pirenaica *, Archivo español de arte y arquelogía $1 \mathrm{I}, 1926$, p. 287.288.

6. Notes sur les tympans aragonais „, Bulletin hispanique XXX,1928, p. 199-203 irééd., Études d'art roman, Paris, 1972, p. 231-2/2; et Les débuts de la sculpture romane espagnole. Leon. Jaca. Compostelle, Paris, 1938, p. 106 et 129.

7. Antonio Ubieto Arteta, \& El románico de la catedral jaquesa y su cronología *, Principe de Viana XXV, 1964, $\mathrm{n}^{\circ}$ 96-97, p. 187-200) (avec l'édition des textes controversés ; le texte du * concile de Jaca de $106^{\circ} 3$ est aussi publié par Federico Balaguer, a Los límites del obispado de Aragón y el concilio de Jaca de 1063 ,, Estudios de edad media de la corona de Aragon IV, 1951, p. 135-138).

8. Une sculpture du style de Bernard Gilduin à Jaca s, Bulletin monumental 131/1, 1973, p. 7-9 et \& I a sculpture romane de la cathédrale de Jaca. Ftat des questions », art. cit (n. 1), 1979 , p. 85 .

9. Marcel Durliat, - Les origines de la sculpture romane à Jaca », CRA/, 1978, p. 365, fin $\mathrm{xI}^{r}$ et début XII siècle; Willibald Sauerländer, \& Romanesquel Sculpture in its Architectural Context ", dans The Romanesque Frieze and its Spectator. The Lincoln Symposium Papers, éd. Deborah Kahn, Londres, 1992, p. 19. 


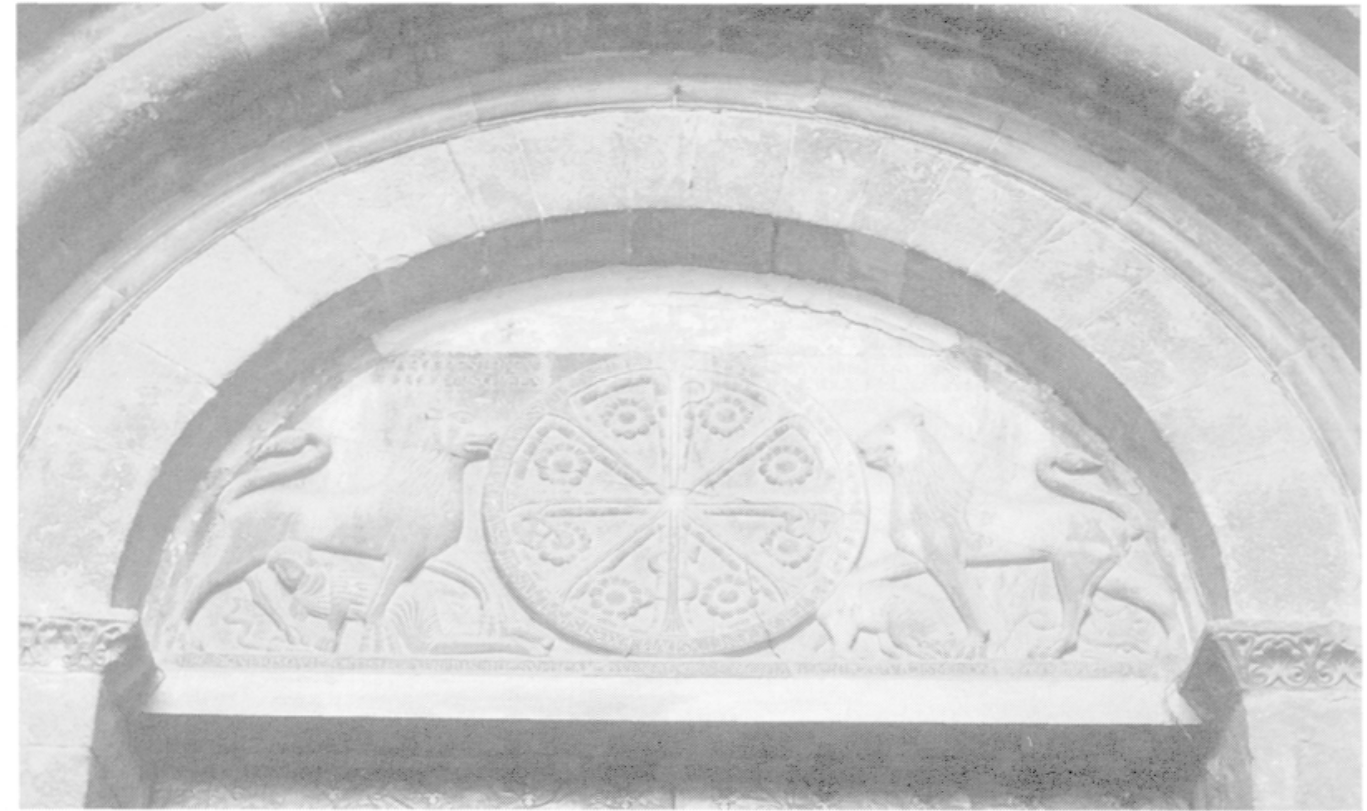

Fin. 1. Jaca cathédrale. tympan de la facade oceidentale. photo Fermander Galtier Warti.

la Serós. el San Vartín de L neastillo. Le lion de ganche est dressé au-dessus diun homme colemdu entre ses pattes el qui éarle de sa poilsine un serpent. Du-dessus de la têle du lion, en deux lignes. on lil :

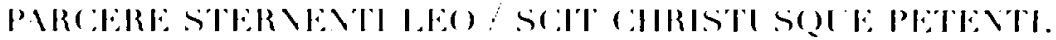

"Le lion sait cpargner celui qui est élendu à terre, el le

Christ celui qui l’imploren figg. 2 .

Ie live des Proverbes XXX. 30 aite le lion eomme "le plus fort de lous les amimaux". el Paneien Teslament presente trois persomages qui ont éle confentés an lion. Samson. Dasid. Daniel. Mais la uous ne sommes pas dans une explieation de lype biblique. Linseription remoie aux bestiaires. Nu départ il y a le

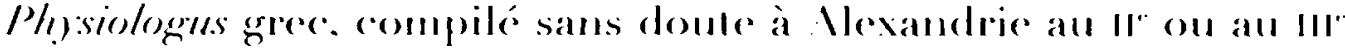
siecle el traduit en latin des le 11 "siecle. I a plus importante lans-

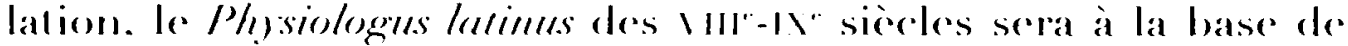
tous les bestiaires médiévaux. Dans le P/gysiologus et dans tous les bestiates le lion est rite en premier car il est le roi des animanx". - 21 .

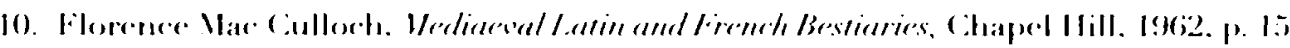




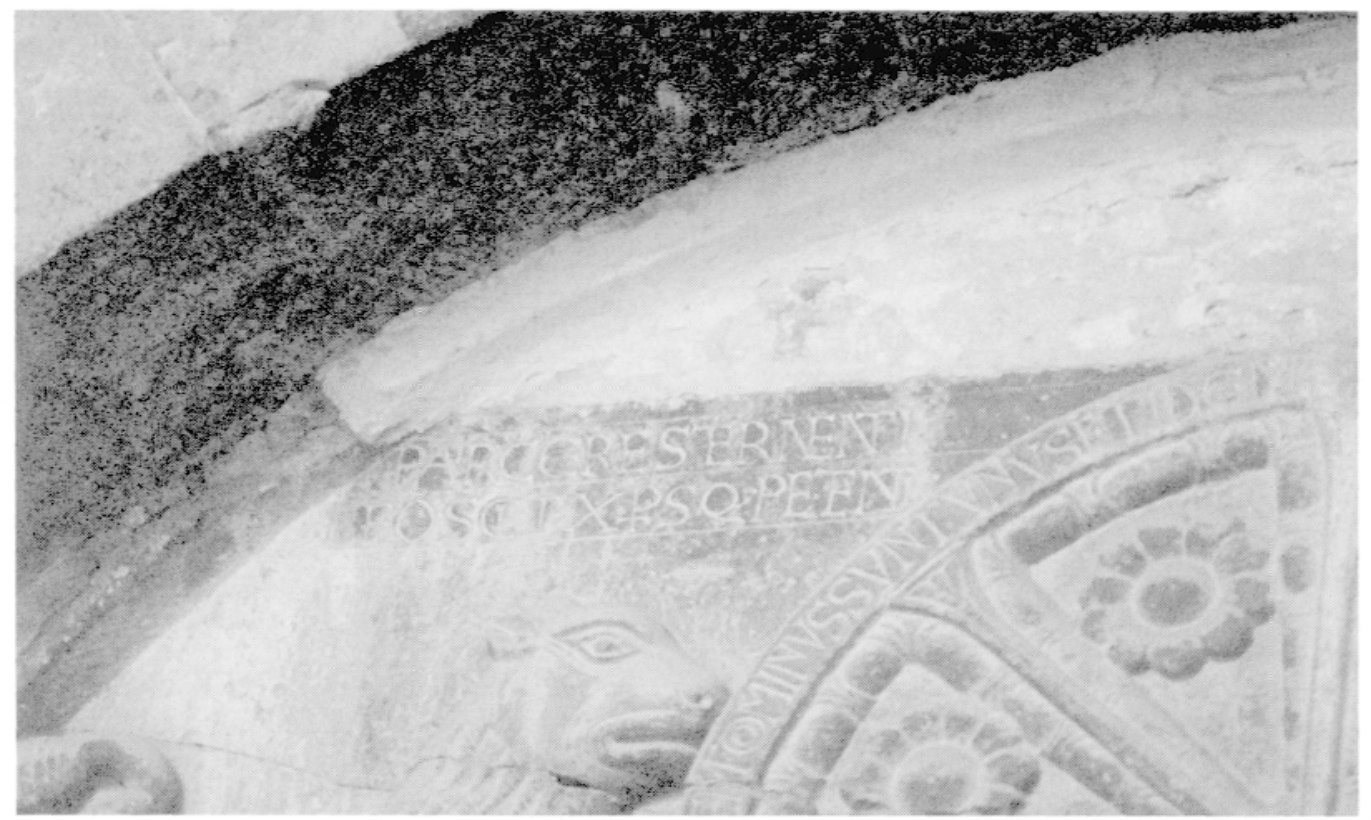

Fic. 2. Jaca. cathedrale, tympan. lion de gauche photo Fernando Galtier Marti.

selon l'inferprétation quen donnent Isidore de Séville, et après lui Raban Maur au $X^{*}$ et le De Bestiis au XI" siocle". El Raban Maur affirme: leo, qui rex est bestiorum, perfortitudinem topum tenet Christi?"

le Physiologus ef les bestiaires allribuent au lion trois caraclieres particuliers, dont deux sont présentés au tympan de Jaca, tandis que le troisieme est peutêtre évoqué dans l'inscription qui aceompagne le chrisme. En premier lieu, le lion épargne reux qui sont aballus. Cóest dójà la convance des auleurs dé l’intiquite: "Le lion, dil Pline l'Incien dans son /fistoire manmedle, est le seul fauve qui montre de la clemence envers les suppliants, il épargne ceux qui sont terrassés" prostratis parcil, ce que

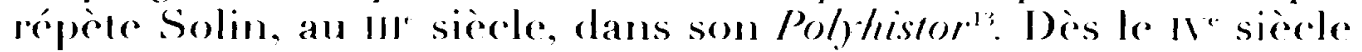
Rufin d'Pquilée, dans son commentaire du verset 9 du chapitre XIIX de la Genose, Catulus leomis .ueda. Ad praedam, fili mei, ascendisti. Requiescens accubuisti m leo, el quasi laena, quis susciabuit

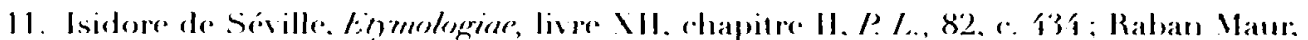

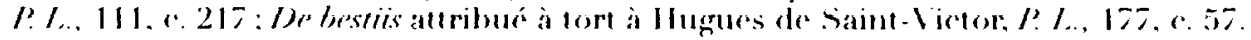

12. I. /., 111., 217.

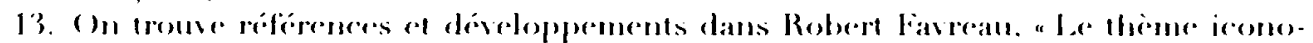

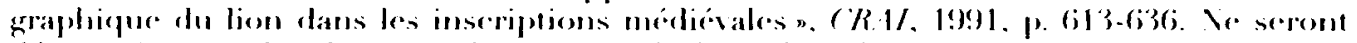

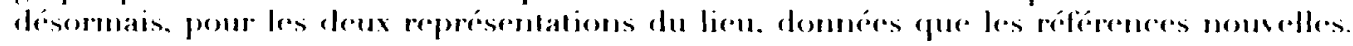


eum, réunit les deux scènes de Jaca : par sa mort et sa résurrection le Christ triomphe du démon (scène de droite), et il sauve la proie du démon, praeda, c'est-à-dire l'homme pécheur et terrassé, prostrato homine et dejecto't' (scène de gauche). On peut suivre, à partir du relevé qu'a donné Nikolaus Henkel ${ }^{15}$, la longue liste de ceux qui, de Rufin et d'Isidore de Séville à Vincent de Beauvais ont appliqué au Christ face au pécheur - à Jaca l'homme qui écarte de lui le serpent. - la mansuétude du lion envers ceux qui sont abattus. "Les naturalistes rapportent que le lion épargne l'homme prostré. La colère du Seigneur sera terrible, mais elle épargnera ceux qui sont prostrés et qui reconnaissent leurs péchés n, commente Rupert de Deutz ${ }^{16}$. C'est bien là le sens du lion de gauche du tympan de Jaca. Cette identification du Christ de miséricorde au lion bienveillant pour le malheureux est parfois, au Moyen Âge, citée comme une invitation au pardon adressée aux puissants de ce monde. C'était le sens de l'inscription qui accompagnait le lion à l'entrée du Capitole à Rome et du distique de Thierry, abbé de Saint-Trond au début du XII' siècle, reproduit en la chapelle Saint-Nicolas du Latran et recopié tant par l'auteur du De Bestiis que par un manuscrit de l'abbaye de Gladbach du XII' siècle :

* La noble colère du lion sait épargner ceux qui sont abattus. Toi aussi qui domines dans le monde, fais de même. ${ }^{17}$

On notera la parenté entre le vers de Jaca et le vers de Thierry de Saint-Trond, parcere sternenti leo scit d'une part, parcere prostratis scit de l'autre. Le second hémistiche du vers de Jaca est sans doute inspiré de l'un ou l'autre passage des quatre évangélistes où est citée la prière de demande : Petite, et dabitur vobis (Matthieu, VII, 8 ; Luc, XI, 9, etc.). Le thème de la pénitence est extrêmement fréquent à la façade des églises, le fidèle étant invité à regretter

14. P. L., 21, c. 302, et Corpus christianorum. Series latina XX, p. 193 (Turnhout, 1961). Rufin est copié par Paschase Radbert, P. J., 120, c. 53.

15. N. Henkel, Studien zum Physiologus im .Mittelalter, Tübingen, 1976, p. 16/167 (Hermaea germanistiche Forschungen, neue Folge, hgg. von Helmut De Boor et Hermann Kunnisch, band 38 ).

16. P. I., 168, c. 193-194, référence que ne donne pas Henkel.

17. Clemens M. M. Bayer, "Der verschollen Vitus-Schrein des (jladbacher Münsters : Inschriften und Ikonographie ", Annalen des historischen Vereins für den Niederrhein 195, 1992, p. 89 'fig. 8 ; et (F). I e manuscrit est aujourd'hui à Cambridge (Massachussets, Harvard University Library, (Coll. Philipp Hofer, Ms. Typ. $202 \mathrm{H}$, fol. $1 \mathrm{r}^{\dot{c}}$. C'est aussi la leçon des Contes moralisés de Nicole Bozon, frère mineur, éd. I ucy Toumin-Smith et Paul Meyer, Paris, 1889, p. 54 (Société des anciens textes français,. Un lion passant avec la légende + NOBII.IS PRIMIS DICI SOLET IRA LEONIS figurait sur les sceaux d'Arles (Aix, Bibl. Méjanes, ms. 760 :536, R. 444;, P. 165-166;. 


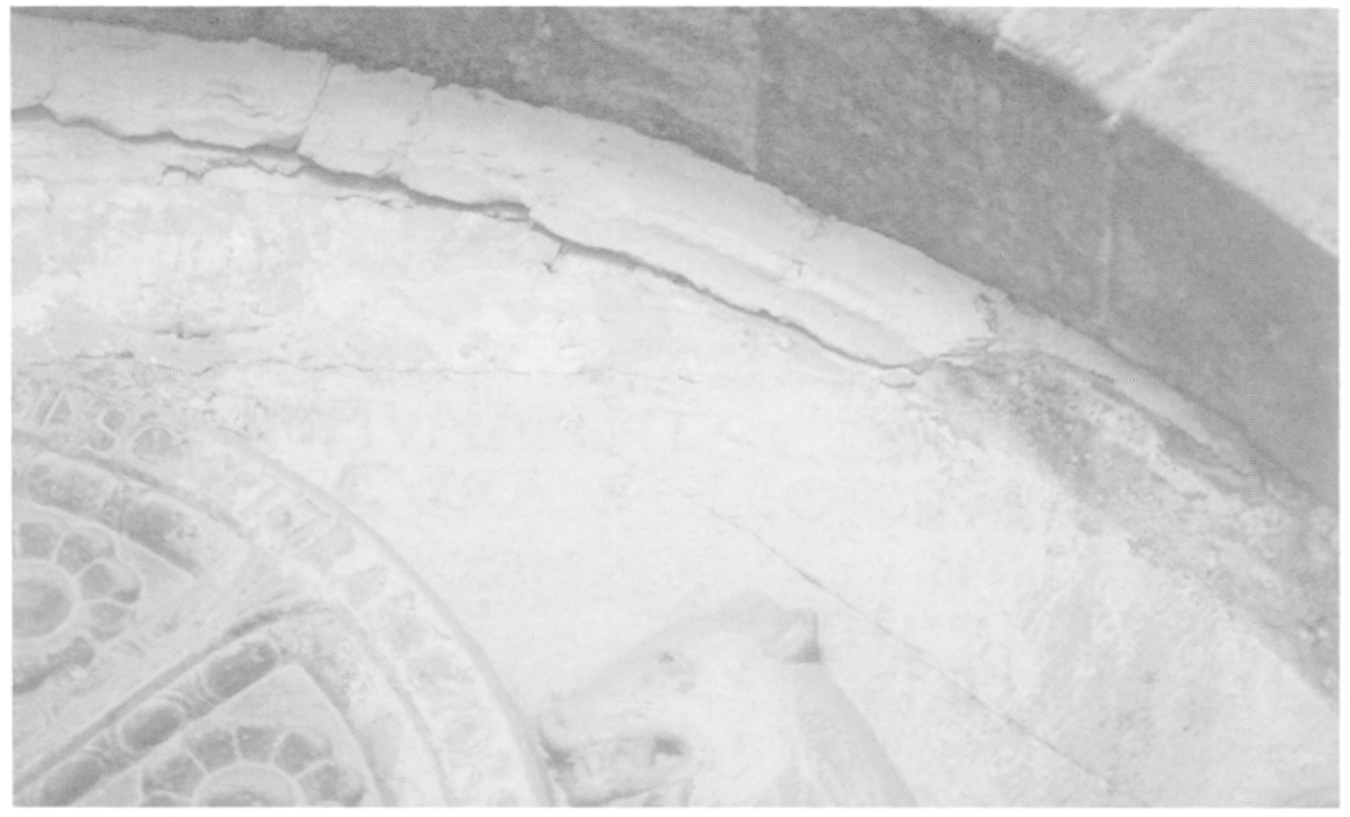

Fin: 3. Jara. cathedrale. prompan lion de droite photo termandoc (ialliere Marti .

ses faules ed a avoir le sentiment de sa fablesse avant demlrer daus la maison du Seigneur. ()n a, a Jaca, mo exemple. parfaitement réussi, deme inseription qui en un seul vers émonce ume penser piche de sems.

Sur le Mmpan le lion de droite foule aux pieds un ours et un basilie et la aussi ume formule admimablement eondensé en un vers domter le sems:

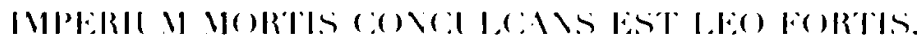

"Il est le lion forl qui foule à ses pieds lempire de la mort." lig. 3

lieconographie lait appel à un autre lmail du lion déceloppé par

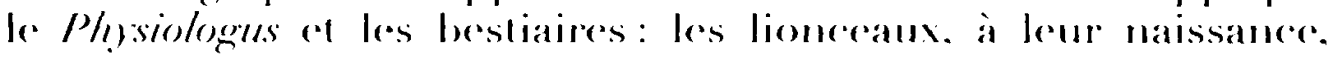
demenrent eomme sans ve pendant trois jours et trois muils. puis leur pere arrive. el par son souffle on soll rugissement il leur

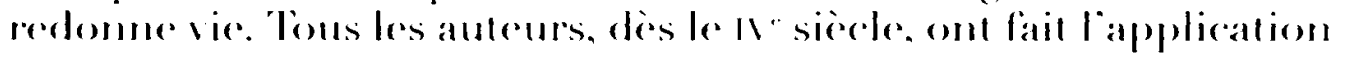
de ce cameleme an christ mort et ressuscile. a commencer par

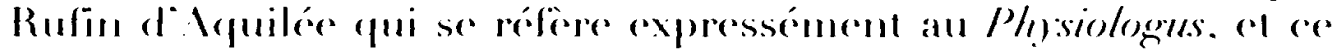
symbolisme sest appliqué an lion qui représente l'évangéliste Vare. I)es inseriptions cóléhrant le lion comme image de la Résur- 
rection se trouvent sur l'ambon d'Henri II à la cathédrale d'Aix-laChapelle, au tympan roman d'Armentia, sur le flabellum roman de Kremsmünster, sur le crucifix de l'abbé Henri I"r à Engelberg, sur la croix de l'abbaye de (Clairmarais à Saint-()mer au XII" siecle, sur des vit raux des cathédrales de Bourges et de I yon au XII" siecle, ainsi que dans les enluminures de nombreux évangéliaires.

linscription qui accompagne le lion de droite du tympan de Jaca fait référence à la fois au (hrist qui, par sa résurrection, a vaincu la mort, et an (hrist qui, par sa mort victorieuse, triomphe de Satan. I e leo fortis s'applique à la première signification : hodie resurrexit leo, leo fortis, de sepulcro (tropaire d'Arles, vers l'an mil) ${ }^{18}$, jus solvit mortem patiens leo fortis (Baudri de Bourgueil), ipse fortissimus leo destruxit mortem (Ifildegarde), hymnes d'Abélard ou d'Aram de Saint-Victor. L'iconographie du lion foulant aux pieds l'ours et le basilic, le verbe conculcare, l'expression imperium mortis renvoient aussi au (hrist définitivement vainqueur du mal, c'està-dire de Satan. l'auteur s'est inspiré du psaume XCI (XC), 13: Super aspidem et basiliscum ambulabis et conculcabis leonem et draconem, mais il a remplacé le lion, qui a dans le psaume un sens péjoratif, par l'ours. Ce dernier et le basilic sont représentés par les bestiaires comme des animaux maléfiques, et saint Bernard voit dans les quatre animaux du psaume les figures du mal's. Le tympan de Jaca s'inspire aussi de l'épître aux llébreux (II, 14-15) : "Puis donc que les enfants avaient cette nature de chair et de sang, il s'en est revêtu également afin, par sa mort, d'anéantir celui qui détenait l'empire de la mort, c'est-à-dire le diable - qui habebat mortis imperium, id est diabolum - et de délivrer ceux que la crainte de la mort tenait toute leur vie dans l'esclavage. "Rufin d'Aquilée, lorsqu'il applique au ('hrist ressuscité la figure du lion qui redonne vie aux lionceaux, dit bien dans ce sens : leo fuil vincens omnia et debellans et destruxit eum qui habebat mortis imperium ${ }^{20}$. Isidore de Séville"1 ou Anselme de I saon dans la Close ordinaire"22 parleront de même de la victoire du Christ sur al'empire de la mort ".

18. On retrouve: régulièrement par la suite le resurrexit leo fortis dans les tropes de Pâques 'Corpus troparum. III. Tropes du propre de la messe. 2. Cycle de Pâques, éd. Gunilla Björkvall, Gunilla Iversev, Ritva Jonsonn, Stockholm, 1982, p. 114, 117 et 13/,

19. P. /., e. 238-213, sermon du (Carême.

20. P. L., 21, 6 303. On trouve aussi l'expression qui mortis imperium subjugasti che\% Arnobe le Jeune au I" siècle :P. L., 53, c. 354,

21. Allegoriae quedam scripturae sacrae (P. I.., 83, c. 106); :... Christum qui in cubili sepuleri, quasi leo, securus, corporis somno victoque mortis imperio, post triduum resurrerit. Voir aussi d'Isidore, les De veteri et novo testamento quastiones (P. L.. 83, c. 279, : in ipsa morte mortis imperium vicit.

22. Clossa ordinaria, P. L., 113, c. 178: Christus ut leo requievit, qui non solum mortis acerbitatem sed et imperium vicit. 
L'inscription à la base du tympan est une apostrophe au lecteur, une leçon morale qui lui est adressée à partir du programme iconographique qui lui est présenté :

VIVERE SI QUERIS, QUI MORTIS LEGE TENERIS, HUC SUPLICANIOO VENI, RENUENS FOMENTA VENENI, COR VICIIS MUNDA, PEREAS NE MORTE SECUNIDA.

« Si tu cherches à vivre, toi qui es tenu par la loi de la mort, Viens ici en suppliant, renonçant aux nourritures empoisonnées. Purifie ton coeur de ses vices, afin de ne pas mourir d'une seconde mort. "(fig. 4-8).

On trouve un vivere quaerit dans une épigramme de Prosper d'Aquitaine au $\mathrm{V}^{\mathrm{e}}$ siècle $^{23}$, et l'expression même de vivere si queris figure au début d'un vers d'un manuscrit du British Museum du XIII" siècle : "si tu cherches à vivre, vis bien, car tu mourras. " La “ loi de la mort " est une expression de l'épître aux Romains (VII, 6), mais aussi une image de tous les temps. Le deuxième vers peut être considéré comme une référence aux deux lions du tympan. Le fidèle est invité à une humble demande au secours du Seigneur (suplicando), qui épargne celui qui l'implore (parcere scit... Christusque petenti). Il doit renoncer à tout ce qui est mauvais (fomenta veneni), c'est-à-dire à ces forces du mal, à Satan qui tient l'empire de la mort, que le Seigneur a foulé aux pieds (conculcans). Dès lors, si son cœur est purifié, il ne mourra pas d'une seconde mort, c'est-à-dire de la mort ultime et définitive, celle de l'âme comme le dit le troisième vers. Cette mors secunda est une expression propre à l'A pocalypse ${ }^{25}$. Elle a été reprise par Commodien dès le III' siècle, puis par Fortunat, Eugène de Tolède, et, à l'époque carolingienne, dans la vie de saint Gall et dans la Passion de Pierre et de Paul et autres auteurs ${ }^{2 i}$. On trouve la construction même de l'inscription de Jaca dans une hymne liturgique ${ }^{27}$ :

23. P. L., 51, c. 502 .

24. Hans Walther, Carmina Medii Aevi posterioris latina, II/5. Proverbia sententiaeque Latinitatis Medii Aevi, Göttingen, 1967, n 33999 b, p. 876.

25. Apoc. II, $11 ; \mathrm{XX}, 6$ et $14 ; \mathrm{XXI}, 8$. On peut voir Barthélemy Hauréau, a Notice sur le manuscrit 712 des manuscrits latins de la Bibliothèque nationale $*$, Notices et extraits des manus. crits de la Bibliothèque nationale et autres bibliothèques XXXIII, I're partie, Paris, 1890, p. 199 :

Ergo dum vivis te corrige, ne moriaris,

Nam nisi corrigeris perpetuo moreris

Et victor mortis auditum claudet tibi mortis...

26. Otto Schumann, Lateinisches Hexameter-Lexikon. Dichterisches Formelgut von Ennius bis zum Archipoeta, III, Munich, 1981, p. 437 (M. G. H., Hilfsmittel, 4, 3). Pour Eugène de Tolède, P. $L ., 87$, c. 394.

27. Hymne de corpore Christi du $\mathrm{XV}^{*}$ siècle, Analecta hymnica medii aevi. XV. Pia diactamina. Reingebete und Leselieder Erste Folge, éd. Guido Maria Dreves, Leipzig, 1893, p. 54. 
LES INSCRIPTIONS DI TYMPAN DE LA CATHEDRALE DE JACA 5/3

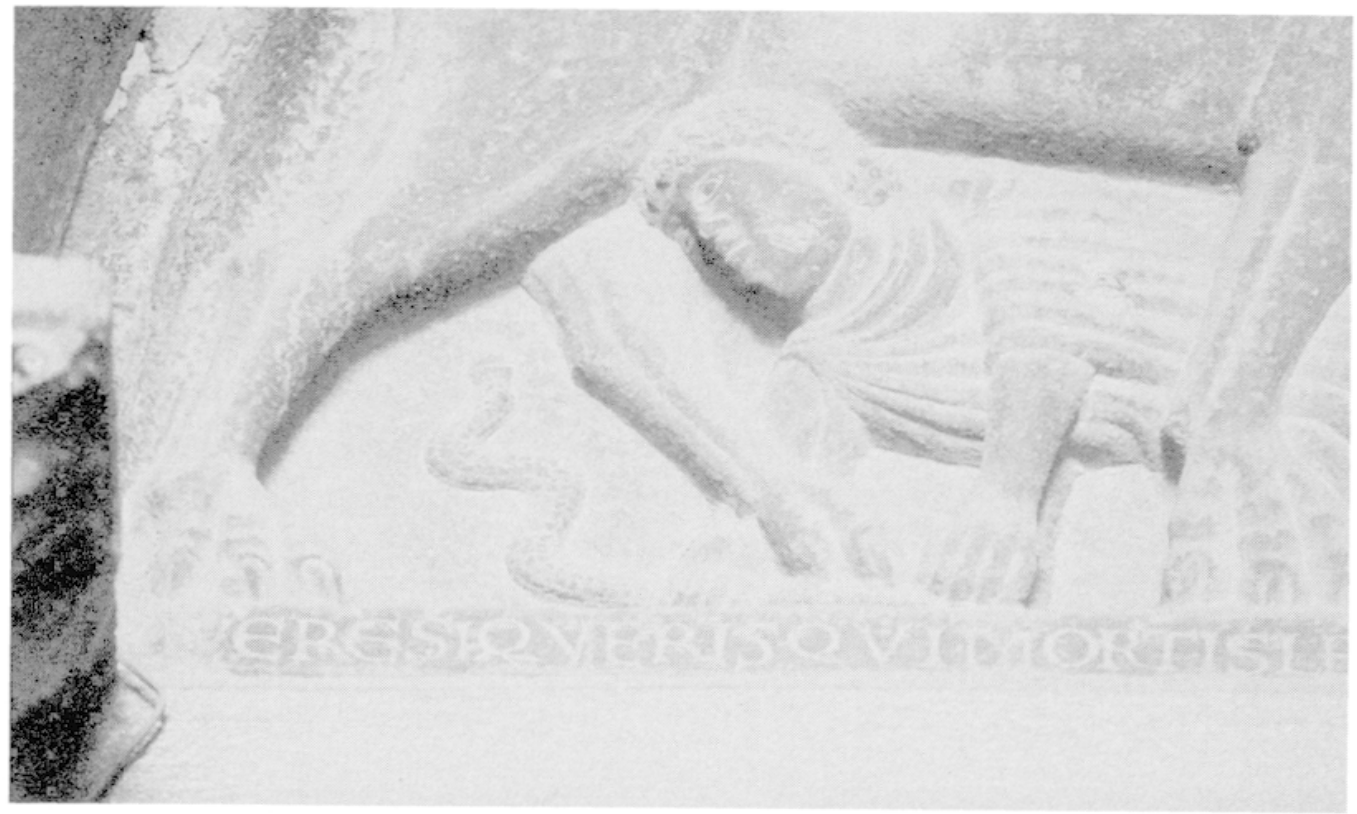

Fic: 4. Jaca, cathédrale. inscription au bas du tympan photo Fernando (jaltier Marti).

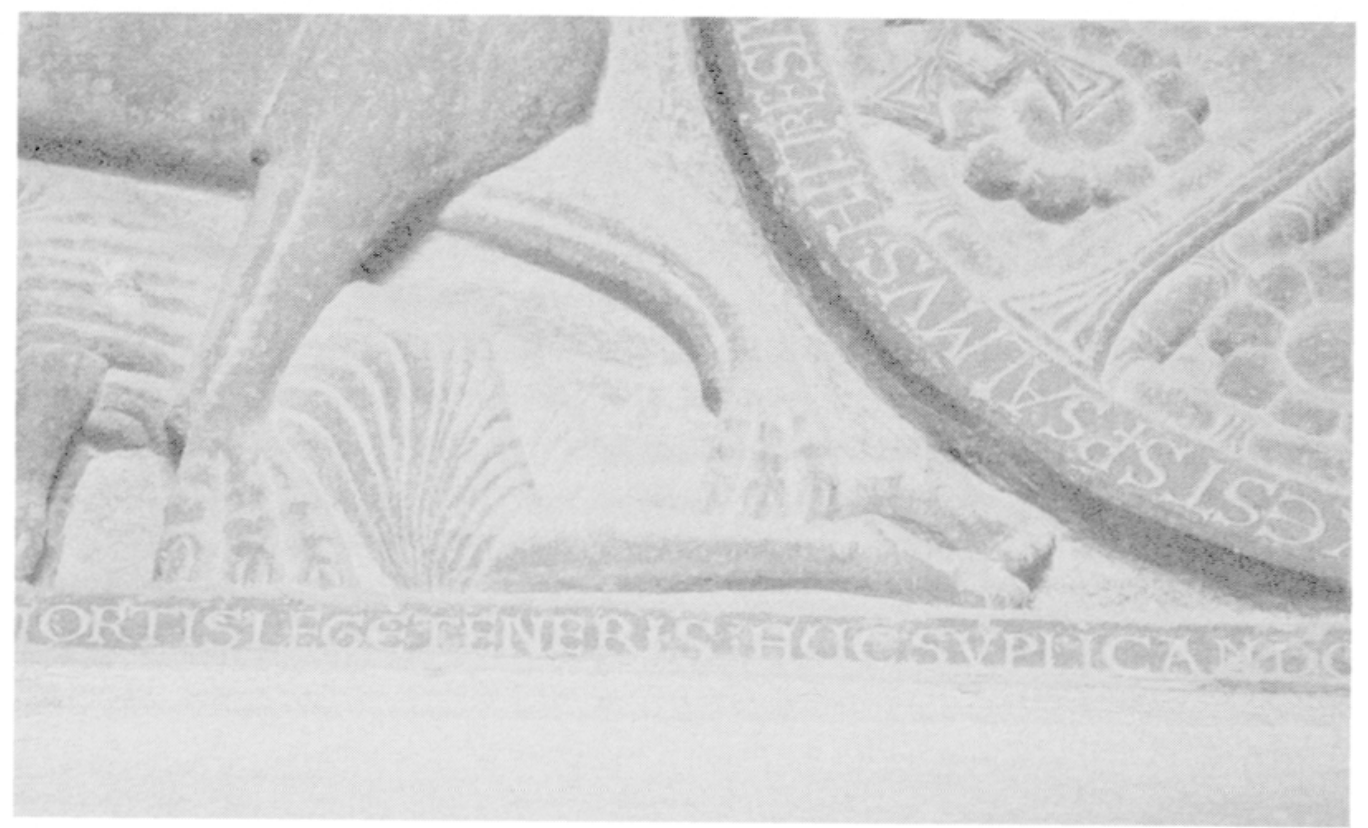

Fir. 5. Jaca cathédrale, inscription au bas du tympan photo Femando Galtier Vlarti . 


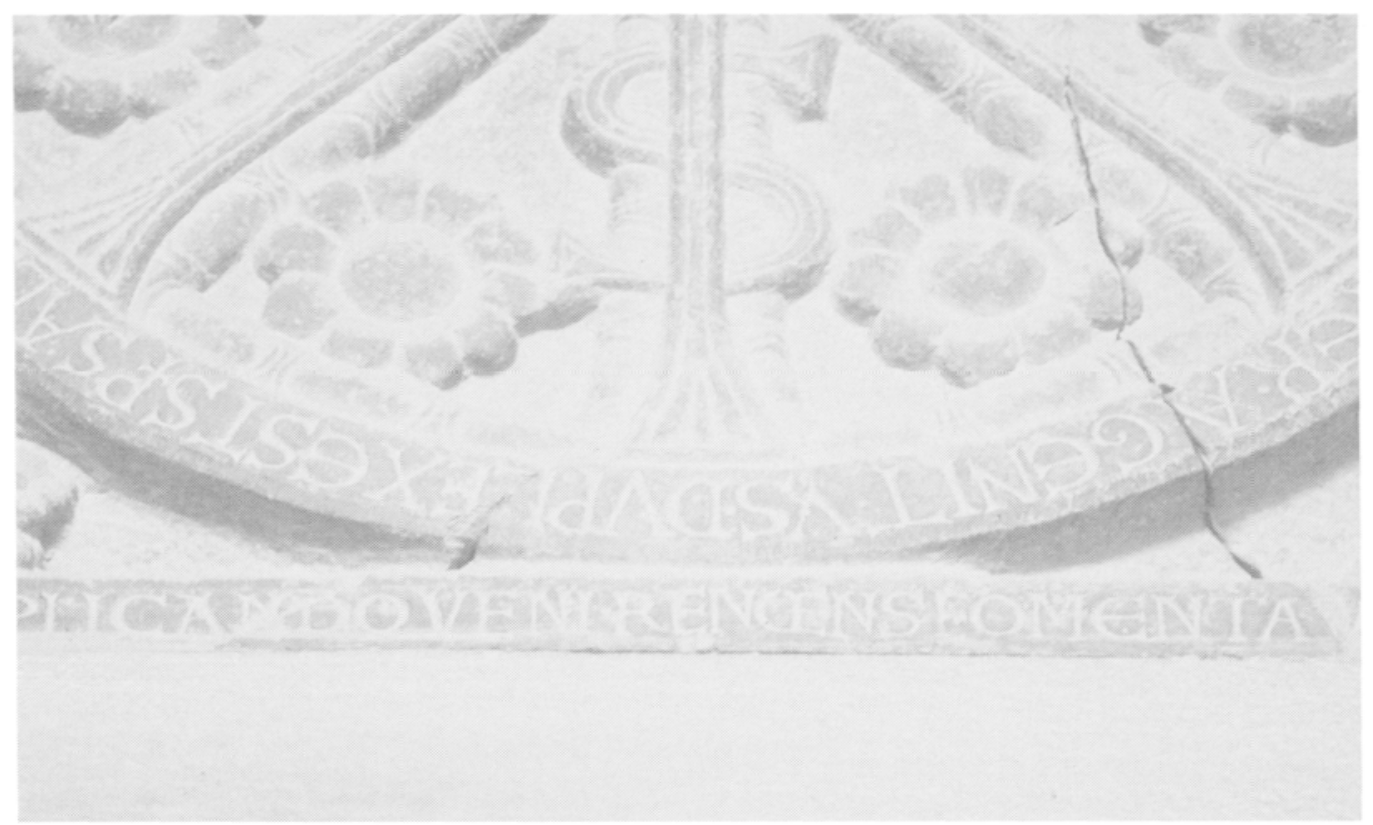

Fir. (i. Jaca cathedeale, inseription an bas du lompan photo Fernatudo Cialtier Varti.

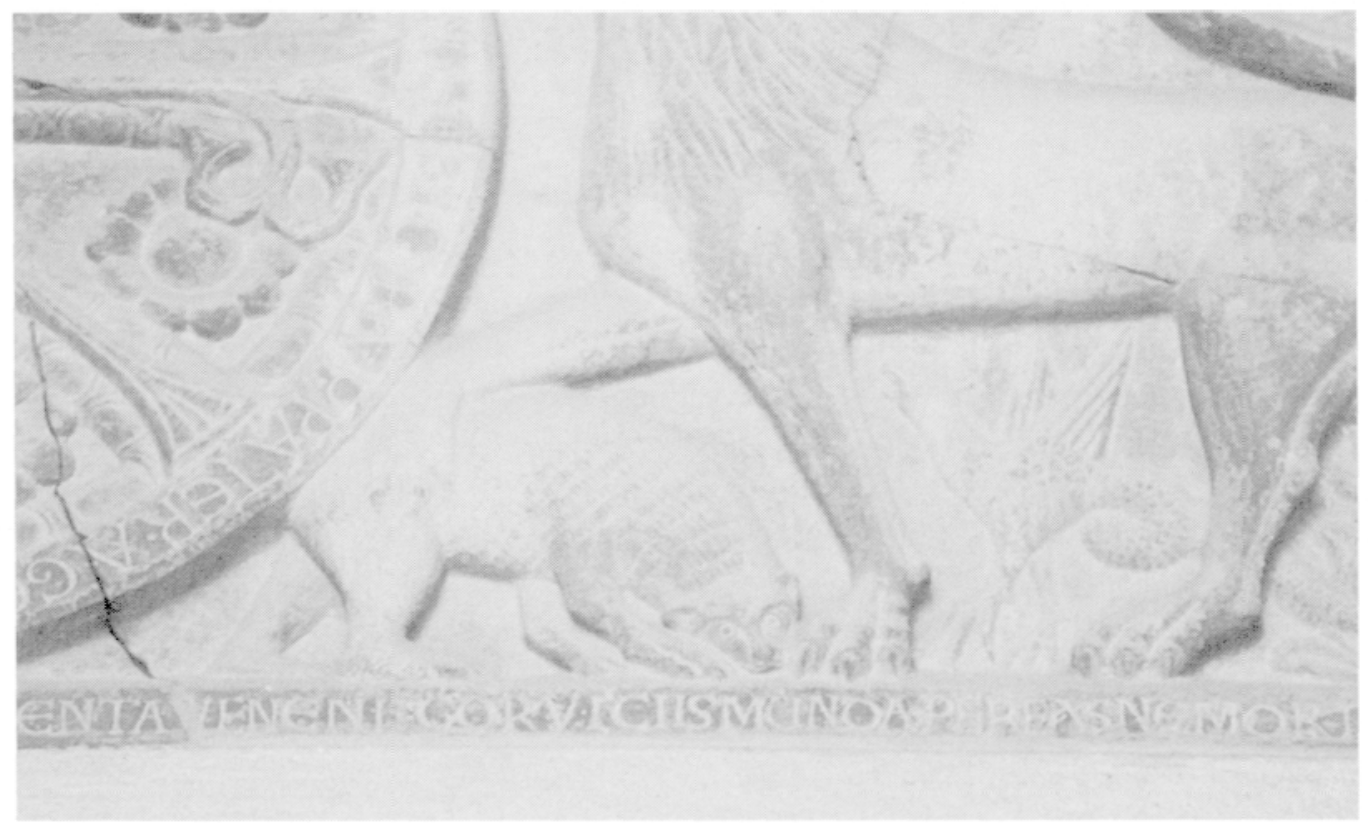

Fur. 7. Jaca cathédrale. inseription an has du tympan photo Fernando Caltier Varti 


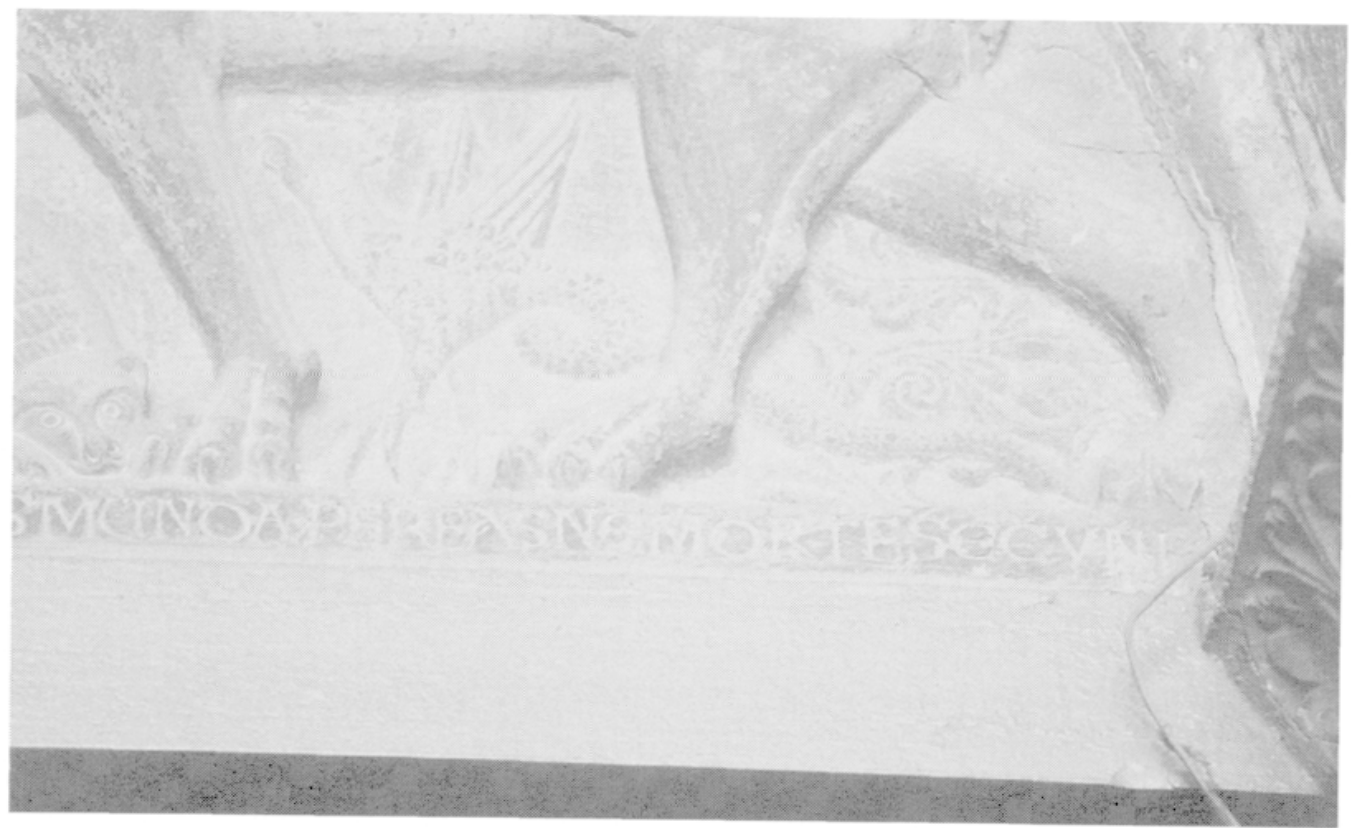

Fir. 8. Jaca. cathédrale. inscription an bas du tympan photo Fermandes Gathier Marti.

\section{Ave caro ('hristi, quare pro me passa finisti}

Hegue ream mumbla, moriar me in morte secumela.

Serafín Vomalejo a, à juste litre, souligné combien le message du tompan "powail se restumer en une velémente exhortalion a

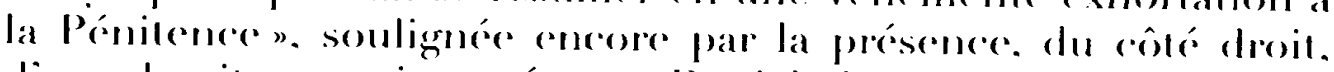
d'un chapitean qui représente Danicel dans la fosse aux lions. secouru par lange el par llabacue. Lors de la réeonciliation des penilents, qui se faisait en grande partice devant la poste au cours de la semaine sainte. le pénitent promoncait la priere de I)aniel:

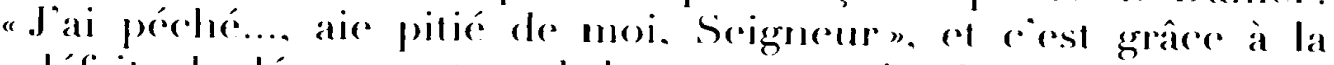
"défaite du démon, auteur de leur mort "selon les lemeses du Pontifical romano-germaniqueres. que les pémitents obtenaient leur pardonis.

le tympan du portail oceidental de la cathédrale de Jaca cest aussi et surloul, vu son carartere momumental. le grand chrisme qui orne le centre de la composition. Iin 1966. sur quatre-vingl-

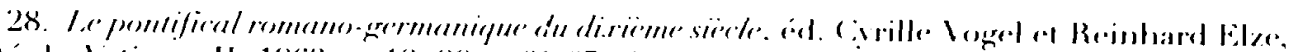

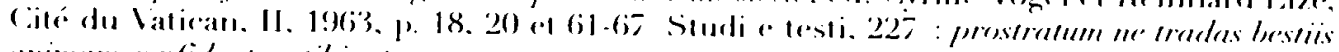
amimerm conficlentem rilsi. ele.

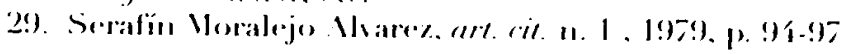


quatre églises romanes qu'il étudiait en Aragon et en Navarre Alain Sené comptait cinquante-neuf églises pourvues d'un tympan sculpté, dont trente-neuf avec un chrisme ${ }^{30}$. En 1985 un volume consacré aux chrismes du Sud-Ouest de la France, en dénombre deux cent quatre-vingt-cinq, dont plus de la moitié situés sur des tympans (cent vingt-huit) ou des linteaux (vingt): Béarn, Gascogne, Comminges, comté de Foix, et jusqu'à la vallée de la Garonne ${ }^{31}$. Mais les chrismes sont très rares en Pays basque et absents en Roussillon, comme dans les Asturies et en Catalogne. Jacques Fontaine a écrit à propos de la croix des Asturies, qu'accompagnent l'alpha et l'omega : « Dans l'ordre de la spiritualité individuelle et collective, ascétique ou politique, la croix est sentie, ainsi qu'en bien d'autres terres occidentales du haut Moyen Age, comme un signe surnaturel de la victoire sur les forces du mal et du Malin. » $^{32}$ Le même langage peut convenir, semble-t-il, au chrisme d'Aragon qui se présente très ordinairement avec la forme de la croix et l'accolade de l'alpha et de l'omega. Peut-être aussi la fréquence du chrisme aux tympans des églises en ces régions correspond-elle à une affirmation de foi, sans représentation du Christ sous une figure humaine, face au monde islamique. On retiendra encore cette belle formule d'Henri Focillon : « Le tympan conçu comme le sceau de Dieu sur l'église a trouvé en Aragon son expression absolue et directe ${ }^{33}$ (fig. 9).

Le chrisme représente une façon voilée de dire le Christ, et, de surcroît, à Jaca, l'inscription autour du cercle qui l'entoure lui confère une valeur trinitaire. On peut ainsi penser, d'une certaine façon, au troisième caractère donné au lion dans les bes. tiaires : il aime aller par les hauteurs, et si alors il sent l'odeur des chasseurs, de sa queue il efface ses traces. " Ainsi notre Sauveur, dit l'auteur du De bestiis au XII' siècle, envoyé par le Père d'en haut a couvert les traces de sa divinité en prenant chair de la Vierge Marie, afin que le diable, ennemi du genre humain, ignorant du mystère de son incarnation, s'efforce de le tenter seulement comme un homme. Quant il a voulu souffrir sa passion pour nous, le diable pensa vaincre par la mort celui que, vivant,

30. Alain Sené, * Quelques remarques sur les tympans romans à chrisme en Aragon et en Navarre ", dans Mélanges offerts à René Crozet, I, Poitiers, 1966, p. 365-381.

31. R. Favreau, B. Mora, J. Michaud, Corpus des inscriptions de la France médiévale, 10. Chrismes du Sud-Ouest, Paris, 1985.

32. L'art pré-roman hispanique, I, La Pierre-qui-Vire, 1973, p. 337.

33. L'art des sculpteurs romans. Recherches sur l'histoire des formes, Paris, 1936 (2r éd., 1964), p. 154; voir aussi Marcel Durliat, art. cit. (n. 9), p. 381 et 383 : * un motif qui deviendra en quelque sorte canonique dans la région pyrénéenne et en Gascogne à l'époque romane, celui du chrisme imprimant le sceau de Dieu sur la porte de l'église. * 


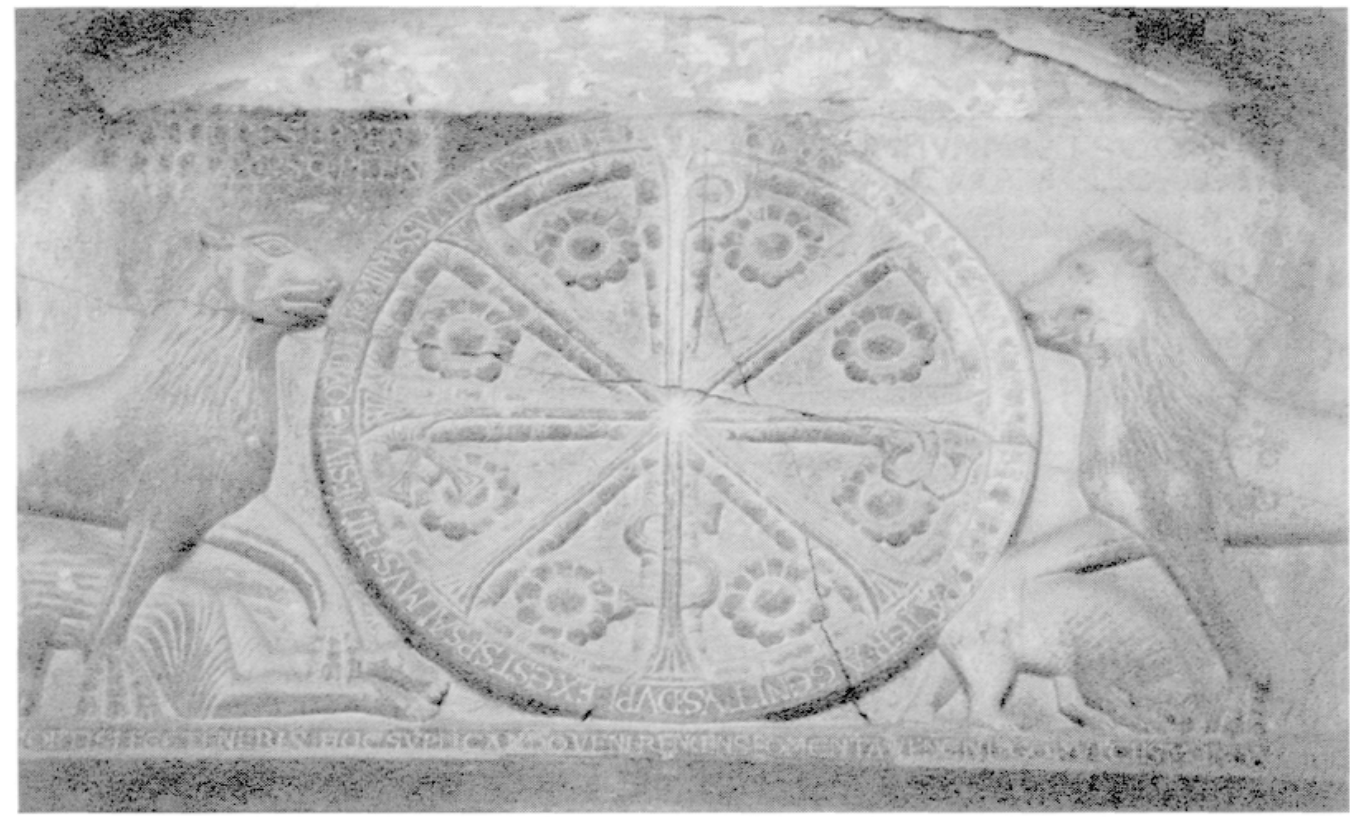

Fir. 9. Jaca, cathédmale, tympan, chrisme central photo Juan F. Fisteban I.corente,

il navait pu dominer. Wais par sa propre puissance Il est ressuscité des morts... a rendu captive sa captivité en faisant preuve de sa divinite. " "

Linscription gravée dans le cercle qui entoure le chrisme de Jaca comprend trois vers:

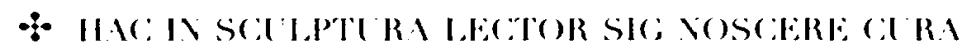

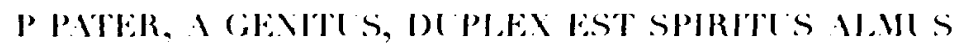

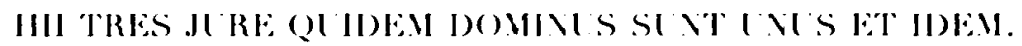

"En cette sculpture, prends soin de reconmaitre, lecteur, Pest le Pere, $\triangle$ lo Fils, la lettre double l'Esprit Saint Ces trois sont à juste titre un seul el même Seigneur" (fig. 10 et 11 ).

Ies variantes de lecture du premier vers, sic; ou sic: vosckekt, SI GosckRt, sicivo scark, ne portent pas à conséquence pour le sens de cet hexametre leonin riche. On trouve les rimes riches cure avec plura, jura, ora, fuura, une douzaine de fois dans les inscriptions françaises des $\mathrm{XII}-\mathrm{NII}$ " siccles, les premières à dale certaine vers 1106 et en 1107 . Thois vers du xil" siecle ont ce méme 


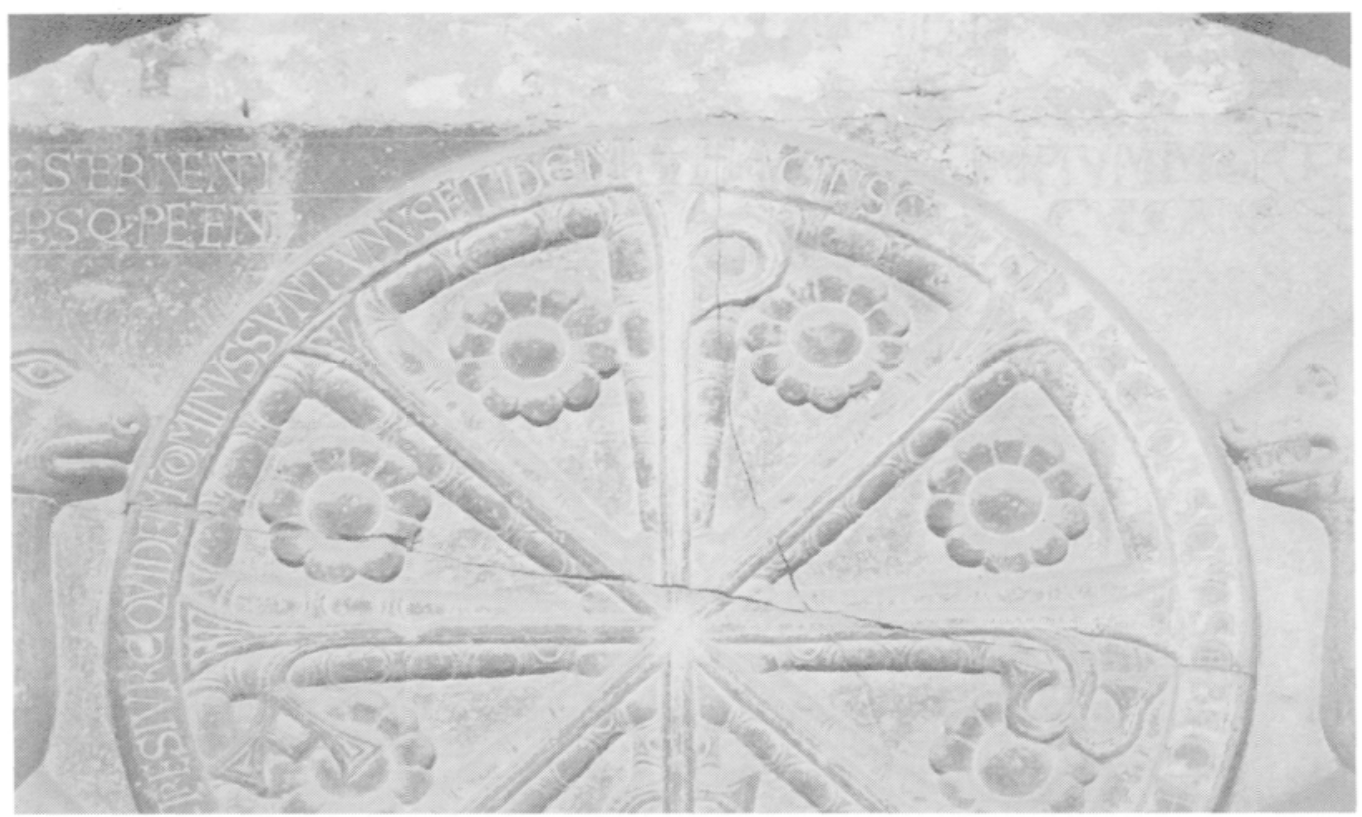

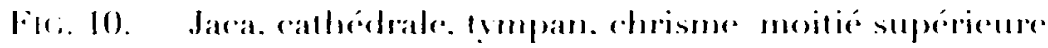
photo Juan is Esteban losente.

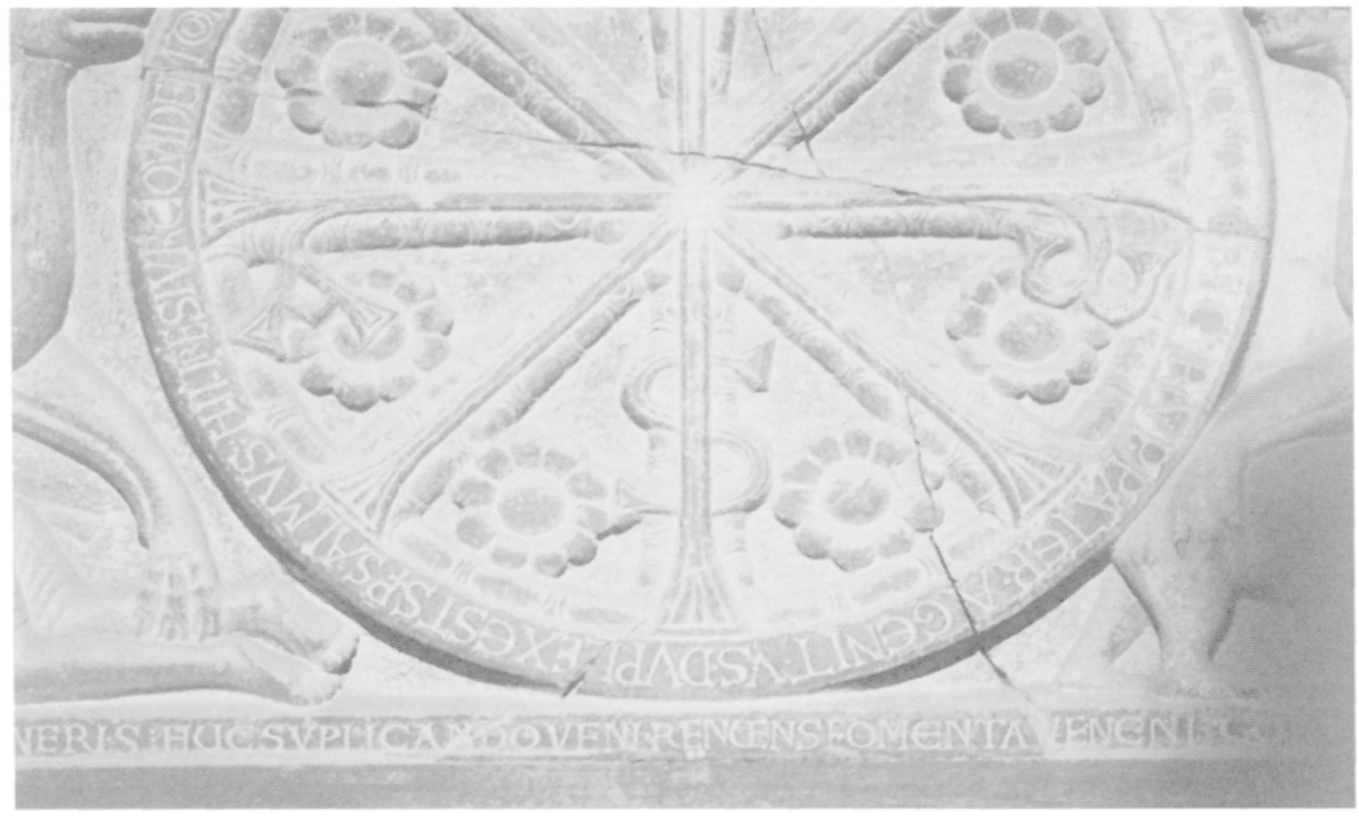

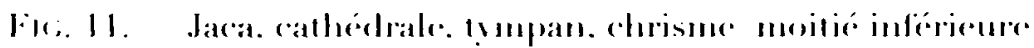

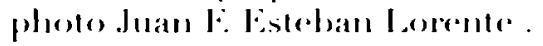


type de rime riche avec le sens même de l'inscription de Jaca. On trouve dans les ceuvres de Baudri de Bourgueuil :

\section{Hac ex pictura, si de te sit tibi cura ${ }^{35}$.}

dans la chronique d'Othon de Freising:

$$
\text { Iac ex scriptura, lector, si sit tibi cura }
$$

et gravé sur un lion roman provenant de la cathédrale de Salzbourg :

\section{Hac celatura, Bertrammi provida cura ${ }^{35}$.}

le troisième vers, qui rappelle la doctrine trinitaire fondamentale, un seul Dieu en trois personnes, ne pose aucun problème d'interprétation. On a délaissé l'expression la plus commune, trinus et unus, que l'on trouve chè Eugène de Tolède ${ }^{\text {ix }}$, et après lui chez, les poètes carolingiens et dans une série d'inscriptions, à Bucchiniacho en Italie du Sud, à Worms-Neuhausen en Allemagne, au Musée national du Moyen Âge ("Sluny") à Paris, à la cathédrale de Sens, et à la cathédrale de Tournai. Ici on a retenu un unus et idem qui est employé au milieu du XI" siècle par le poète Garnier de: Bâle ${ }^{3 ! !}$.

Une vingtaine d'auteurs ont pris position sur le deuxième vers, et, pour cing d'entre eux, dans des études consacrées aux inscriptions du tympan". Trois interprétations en ont été données jusque-lä". la plus ancienne est celle retenue par Gaillard, Weishach, Vivès, Uranga Galdiano et Iñiguez Almec, Caamaño Marti-

35. Jes reuveres poŕtiques de Baudri de Bourgureil (1016-1130), ed. Phyllis Abraham, Paris, $1926, n \cdot 26, p .7$.

36. И. (.. II., Scriplores, 20, p. 103.

37. (Ce lion roman est placé aujourd'hui dans un passage sous voûte au n" 16 de la rue Sigmund-Haffiner.

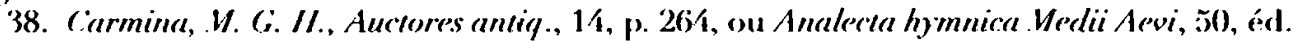
Dresde, 1907, p. 9/4.

39. Ilis solidare fidem quibus est Deus umus ot idem P. W. IJoogterp, Warmerius Basiliensis, S) modus 'Archives d'histoire dortrinale en litteraire du Moyen Age, 8, 1933, p. 389).

40. Viguel Jole, "Tres inscriperones de la cathedral de Jaca ×, Pirineos 9, 1953, p. 421432; José Lives, a las leyendas epigráficas del tímpano de Jaca ", Ilisponice scecra IX, n" 18 , 1956, p. 391-394: Jesus Maria Caamaño Martinez, "En torno al tímpano de Jaca *, Goya, "1 1/2, 1978, p. 2(0)-207; Dulere (Ocón Alonso, "Problematica del crismón trinitarion,

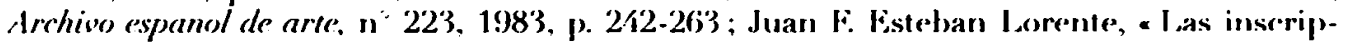
riones del tímpano de la catedral de Jaca *, Artigrama, $n=10$, Revista del departamente de lliseria del Arte Saragosse. 1993, p. 1/3.161.

41. I e premier auteur à citer les inscriptions de Jara est José Yaria Quadrado en 1814. Certains auteurs qui ont traité du tympan n'ont pas cherché de solution au deuxième vers, le sens général d'une interprétation trinitaire du chrismétant évident. 
nez, Ocón Alonso, Sauerländer ${ }^{42}$. Elle consiste à considérer le mot duplex comme qualifiant le fils, qui a la double nature humaine et divine. Il faut alors suppléer un $S$ pour désigner l'Esprit Saint, ou, pour respecter la métrique, considérer que le est a été gravé par erreur en place d'un $S$. Cette solution, qui a été longtemps la mienne, a le mérite de la clarté et de la logique. Elle a deux inconvénients : nécessiter une correction du texte, et retenir pour le Fils, un adjectif duplex, qui lui a, certes, été affecté aux premiers siècles de l'Église, par Tertullien, Chalcidius, Filastre, Claudien Mammert, et par le concile de Nicée lui-même ${ }^{43}$, mais qui a été ensuite abandonné dans la mesure où il pouvait conduire à voir dans le Christ non seulement une double nature mais aussi une double personne, hérésie dans laquelle tomba Nestorius ${ }^{44}$. On abandonnera, de même, triplex pour le remplacer par trinus. Le Spiritus almus est ordinaire dans les textes versifiés car il fournit les deux derniers pieds d'un hexamètre, alors que sanctus, ne permet pas le dactyle obligatoire du cinquième pied ${ }^{45}$. Dans cette interprétation il faut traduire : « $P$ le Père, $A$ le Fils à la double nature, [S] l'Esprit Saint. "

Une deuxième interprétation a consisté à ne pas faire de correction ou complément au texte, et à voir dans le duplex la référence pour l'Esprit Saint à une double procession du Père et du Fils, comme le proclame le Credo dans la forme que lui a donnée l'Occident : qui ex Patre Filioque procedit, une expression dont l'origine est précisément en Espagne. Juan F. Esteban Lorente a développé cette interprétation théologique dans l'article le plus récent consacré aux inscriptions de Jaca ${ }^{46}$. C'est aussi l'opinion de Ricardo Del $\mathrm{Arco}^{4}$. Cette interprétation enrichit le commentaire théologique. Elle a l'inconvénient d'interrompre l'attribution d'une lettre à chacune des trois personnes de la Trinité. Dans ce cas il faut traduire : « $P$ le Père, $A$ le Fils, de l'un et l'autre procède l'Esprit Saint. »

42. Georges Gaillard, Notes sur les tympans aragonais „, Bulletin hispanique, 1928, repris dans Études d'art roman, Paris, 1972, p. 233 (Publications de la Sorbonne. Série - Etudes „, 3); Werner Weisbach, Religiöse Reform und mittelalterliche Kunst, Zurich, 1945, p. 125 ; J. Vives, J. M. Caamaño Martinez, D. Ocón Alonso, voir supra, n. 40 ; José Esteban Uranga Galdiano, Francisco Iniguez Almec, Arte medieval navarro. II. Arte romanico, Pampelune, 1973, p. 248; Willibald Sauerländer, art. cit. (n. 9), 1992, p. 1743 (pour le sens du deuxième vers, p. 19).

43. Duplex essentia (Chalcidius), generatio duplex (Filastre), duplicem statum (Tertullien), ex duplici substantia (Mammert, concile de Nicée).

44. Boèce, Liber de personna et duabus naturis contra Eutychen et Nestorium, P. L., 64, col. 1345.

45. Otto Schumann, Lateinisches Hexameter-Lexiton. Dichterisches Formelgut von Ennius bis zum Archipoeta, V, Munich, 1982, p. 242-245 (M. G. H., Hilfsmittel, 4, 5).

46. Juan F. Esteban Lorente, op. cit. (n. 40), p. 154-158.

47. Fundaciones monásticas del Pirineo Aragonés *, Principe de Viana XIII, 1952, p. $263-398$. 
La troisième interprétation sous-entend littera après duplex, et conduit à traduire: " la double lettre est l'Esprit Saint. " Les auteurs proposent alors de voir dans la double lettre le $S$ du chrisme ou l'oméga qui fait pendant à l'alpha. Pour le $S$ se prononcent Del Arco, Sené, Durliat ${ }^{18}$. On retrouve alors ainsi la première lettre de Spiritus, sans que l'on puisse bien voir une lettre double dans le $S$. Il a été aussi indiqué qu'un petit $S$ apparaît dans l'inscription, mais c'est après $S P S$, et le tracé semble bien correspondre à une erreur du graveur'i. Pensent que c'est l'oméga que désigne la double lettre Duran Gudiol, Canellas Lopez et San Vicente, Buesa Conde, Lafuente et Lacarra" ${ }^{\text {n, }}$ tandis que Dolç fait état de la double possibilité du $S$ ou de l'oméga ${ }^{51}$. Les partisans de l'oméga avancent que la lettre correspond à un double $\mathrm{O}$. Mais on ne voit pas bien pourquoi l'oméga désignerait l'Esprit Saint. Dans l'étude la plus récente Esteban Lorente a proposé de voir dans cette double lettre l'initiale du chrisme interprétée comme une lettre latine, soit $X$. Il avance à ce sujet un passage des Étymologies d'Isidore de Séville : $X$ littera usque ad Augusti tempus nondum apud Latinos erat; sed pro ea $C$ et $S$ ponitur; unde et duplex vocaturi2. Et c'est, effectivement, une partie de la solution.

Il faut retenir une quatrième interprétation. L'auteur de l'inscription a pris, indûment les caractères grecs pour des lettres de l'alphabet latin, et donc le rô $(P)$ pour un $p$, l'alpha $(\alpha)$ pour un $a$, le khi $(\mathrm{X})$ pour un $x$, ce qui donne le mot pax, symbole de la Trinité parce que composé de trois lettres inséparables pour donner le sens. Il faut lire l'exposition sur la lettre de Paul aux Éphésiens écrite par Atton, évêque de Verceil (924-vers 960) pour trouver un commentaire complet de l'inscription trinitaire de Jaca:3. Atton commente Éphésiens II, 13: Nunc autem in Christo Jesu vos qui aliquando eratis longe, facti estis prope in sanguine Christi. "Sans le sang du Seigneur personne n'approche de Dieu... Ainsi il est notre

18. Ricardo del Arco, op. cit. (n. 3), p. 297 ; Alain Sené, art. cit. (n. 30), 1966, p. 375 ; Marcel Durliat, art. cit. (n. 9), p. 383.

49. José Gudiol Ricart, Juan Antonio Gaya Nuno, Ars Hispaniae. Historia universal del arte hispanico. V. Arquitectura y escultura románicas, Madrid, 1948, fig. 196.

50. Antonio Duran Gudiol, * Jas inscripciones medievales en la provincia de Huesca *, dans Estudios de edad media de la conona de Aragon, VIII, Saragosse, 1967, p. 56-58; Angel Canellas Lopez, Angel San Vicente, Aragon roman, La Pierre-qui-Vire, 1971, p. 159; Domingo Buesa Conde, Las catedrales de Aragón, Saragosse, 1987, p. 70 et n.; Miguel A. Jafuente, introduction à Maria del Carmen Lacarra Ducay, Catedral y . Museo diocesane de Jaca, 1993 ícités par Juan F. Esteban Lorente, op. cit. (n. 10), p. 146-147,.

51. Miguel Dolç : voir n. 40; Susan Havens (Cadwell, . Penance, Baptisma, Apocalypse: The Easter Context of Jaca Cathedral's West Tympanium *, Art Histor. 3, 1980, p. 26 sqq.

52. P. L., 82, c. 80.81 (livre I, chap. V, \$11).

53. P. L., 134, c. 554-555; Suzanne Fonay Wemple, Atto of Vercelli. Church State and Christian Society in Tenth Century Italy, Rome, 1979 (Temi e testi, 27); A. Frugoni, a Attone di Vercelli „, dans Dizionario biografico degli Italiani, Rome, 4, 1962, p. 567-568. 
paix... Si le Christ est la paix des élus, en conséquence ceux qui n'ont pas le Christ ne sont pas dans la paix. "Et après son renvoi à saint Augustin - et les chanoines de Jaca suivent la règle dite de saint Augustin -- Atton de Verceil poursuit : « La paix (pax) est écrite en trois lettres, et non plus. Considère donc que le Père est dit $P$, que le Fils est appelé alpha, parce que, de même que le $a$ est la première lettre de l'alphabet, ainsi le Christ est dit le commencement, car, comme il était interrogé, il dit qu'il était le commencement"i. A la vérité cette syllabe est longue, et elle est première. Par le fait qu'elle est longue, elle signifie que le Christ n'est pas limité par le temps, mais est éternel ; syllabe parce que le Fils est dans le Père et le Père dans le Fils, et ils ne forment qu'un; première, parce que le Fils n'est pas second, comme le montre cette affirmation : Je suis l'alpha et l'oméga, le premier et le dernier"s, le dernier parce qu'il a voulu naître et mourir. La troisième lettre à la fin, le $X$, signifie que l'Esprit Saint ne tend pas à la fin mais excelle toujours en la suprême majesté. Ainsi l'Apôtre déclare: préoccupez-vous des

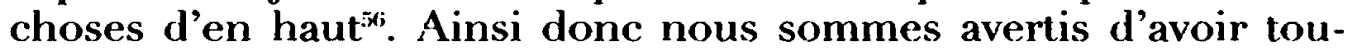
jours l'esprit tourné vers le haut... Afin donc qu'advienne la paix, au $p$ est jointe la voyelle $a$, pour que le $p$ ne demeure pas muet, parce que le Père est lié à la voix, et toujours à son Verbe. Mais pour que soit la paix le $x$ est ajouté, qui est une lettre double placée pour deux consonnes, parce qu'elle participe au Père et au Fils et au Saint Esprit. Ces lettres different par leurs noms et par les personnes. Pourquoi ? Parce que l'un est dit $p$, l'autre $a$, l'autre $x$. P est une lettre, mais substantiellement, de même le $a$ est une lettre, substantiellement, et le $x$ une lettre, substantiellement. Ainsi le Père est Dieu par nature, etc. De même que la paix est écrite en trois lettres, ainsi Dieu est Trinité ; et comme la paix, Dieu a le nombre singulier de la Divinité. En cet assemblage de lettres il n'est pas admis de division des trois, pour que la paix soit accomplie. Si tu en retires un, il n'y a plus de Trinité ni de paix. " On a donc dans le texte d'Atton le commentaire le plus explicite qui soit de l'inscription de Jaca, en notant, en particulier, qu'Atton parle du $X$ comme d'une lettre double, duplex, en employant les termes mêmes d'Isidore de Séville ${ }^{j \bar{\gamma}}$, et qu'il commente le $a$ comme une syllabe longue, ce qu'elle est effectivement dans l'hexamètre léonin de Jaca ${ }^{\text {\$\$ }}$. Seul

54. Principium qui et loquor vobis (Jean, VIII, 25).

55. Ego sum Alpha et Omega, principium et finis (Apoc. I, 8); ego sum primus et novissimus (Apoc. I, 17); primus et novissimus (Apoc. II, 8 et XXII, 13). La citation d'Atton est celle de i'Apocalypse XXII, 13 : Ego sum Alpha et Omega, primus et novissimus.

56. Quae sursum sunt sapite, non quae super terram (Colossiens III, 2).

57. Pro ea C' et S ponitur; unde et duplex vocatur.

58. Le a final est bref, sauf à l'ablatif; ici le a est seul et au nominatif: 
le genitus n'est pas expressément cité par Atton, mais il est employé pour désigner le Fils chez les auteurs les plus connus, Isidore de Séville ${ }^{\text {s: }}$, Alcuin ${ }^{(i)}$, Hugues de Saint-Victor ${ }^{\text {(i1 }}$. Cette assimilation du mot pax à la Trinité est reprise en 1181-1182 par l'évêque d'Assise. Rufin, dans son De bono pacis libri duo. "Le mot Pax exprime l'admirable sacrement de la 'Trinité... Le $P$ qui est la première lettre, désigne le Père, le $A$, qui est la lettre du milieu le Fils, le $X$ qui est la dernière, l'Esprit Saint... „Son commentaire est assez différent de celui d'Atton, et beaucoup plus compliqué, sauf pour l'explication de la lettre $A$ représentant le Fils ${ }^{6.2}$. Dans les chrismes du SudOuest de le France trois chrismes ont le mot PAX, soit à part, à Sainte-Engrâce (pax tecum), soit en combinaison avec le chrisme, à Oeyreluy et aux Peintures. Il ne semble pas qu'on y ait recherché une signification trinitaire ${ }^{63}$.

Dans le programme du tympan de Jaca l'appel adressé aux fidèles à faire pénitence, en se confiant à la miséricorde du Christ et en se rappelant que par sa mort il a vaincu le Mal, est de tous les temps. Il s'insère parfaitement dans la période de réforme religieuse que connaît l'Église à partir de la seconde moitié du XI" siècle $^{64}$. En reprenant le thème de la Pénitence auquel elle ajoute celui du Baptême, qui est aussi engagement à renoncer à Satan et à ses ouvres, Susan Havens Cadwell a même mis en rapport le tympan de Jaca avec la disgrâce, en 1086, de l'évêque Garcia qui avait excommunié un favori de son frère le roi Sanche Ramirez ${ }^{65}$. Avec le détournement de sens du chrisme vers une explication trinitaire on est aussi dans une période où le dogme de la Trinité fait l'objet de discussions, de déviations, de réfutations. L'adjonction du Filioque au Credo est un des éléments qui entrent en compte lorsque l'Église d'Orient, avec Michel Cérulaire, se sépare de l'É. glise romaine au milieu du $\mathrm{XI}^{\prime \prime}$ siècle. Certains auteurs distingueront dans la Trinité non seulement trois personnes - ce qui est exact -.. mais trois Dieux. En 1092, le trithéisme de Roscelin de Compiègne sera condamné au concile de Soissons, sous l'impulsion d'Anselme de Cantorbéry, qui écrit, contre Roscelin, un De

59. P. L., 82, c. 271 (Ft)mologius De Trinitate) et 83, col. 915 (De ordine creatorum,

60. P. L.. 111, c. 55.

61. P. L., 171, c. 1079 : Genitus, Natus, Verbum.

62. P. I., 150, c. 159/4-1595.

63. C. I. F. M., 10, éd. R. Favreau, B. Mora, J. Michaud, Paris, 1985, n“ 187,122 et 133.

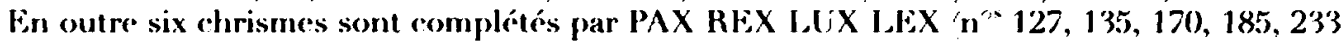
et 254, qui renvoient au ( hrist. Je mot $P \wedge X$ figure dans différentes inseriptions, notamment à la façade 'Robert Favrcau, likudes d'éprigrraphie médiéwale, limoges, 1995, , p. 382 et 556,.

61. Werner Weist)ach, op. cit. in. 12, 1945, p. 125-126; Id., Reforma religiosa. arte medieval. La influencia de (\%un) en el romámion occidental, Madrid, 19/9, p. 133; Ricardo del Arco, art. rit. 'n. 3, p. 297.299.

65. Penance, Baptism, Apocalypse - voir n. 51, p. 34-35. 
fide Trinitatis. Au XII ${ }^{e}$ siècle le conceptualisme de Pierre Abélard est condamné à Sens, le réalisme de Gilbert de la Porrée est corrigé à Paris et à Reims. Rupert de Deutz, Hugues de Saint-Victor, Pierre Lombard écrivent sur la Trinitét ${ }^{66}$. Dans tous ces débats Augustin - sous le règne duquel vivent les chanoines de Jaca - est la référence magistrale incontestée ${ }^{67}$. Les inscriptions du tympan de Jaca doivent être considérées dans ce contexte religieux de réforme des mours et de discussions dogmatiques.

Les inscriptions de Jaca s'insèrent aussi dans le problème général de l'influence française au-delà des Pyrénées - fondations monastiques ${ }^{\text {r.8 }}$, prélats français, croisades, pèlerinage à Compostelle, etc. Cette influence se traduit par l'abandon de l'écriture " wisigothique " pour les litterae gallicae, officialisé par le concile de León de 1091, et par la pénétration de l'hexamètre léonin. Ricardo del Arco indique un a $t$ mozarabe „, et les auteurs de l'Aragon roman disent aussi que le $T$ de PATER semble révéler une influence wisigothique ${ }^{69}$, ce qui n'est pas du tout évident au vu d'une bonne photographie. Le petit nombre d'onciales, la rareté de la ponctuation, le " classicisme " de la majorité des lettres peuvent bien correspondre à la fin $\mathrm{du} \mathrm{XI}^{\prime}$ siècle, et l'écriture est très proche de ce que l'on trouve en France à cette époque, en notant que les inscriptions des tympans de Jaca et de Santa Cruz de la Serós sont les seules en écriture caroline de la province de Huesca pour cette période ${ }^{70}$. Les inscriptions sont toutes en hexamètres lćonins riches, avec des libertés dans les quantités (deuxième vers de l'inscription au bas du tympan), et à l'exception du deuxième vers de l'inscription trinitaire, qui est un hexamètre léonin simple. Il faudrait étudier l'ensemble de ces questions d'écriture et de métrique, ce qui suppose un corpus des inscriptions, de bonnes photographies et une étude plus générale de ce rattachement de la péninsule au reste de la chrétienté, avec aussi l'abandon de la liturgie mozarabe qui est de cette même fin du $\mathrm{XI}^{e}$ siècle.

L'éclairage donné à l'inscription de Jaca par le texte d'Atton de Verceil remet en cause la thèse qui affecte chaque chrisme d'une valeur trinitaire. Jesús María Caamaño Martinez rappelle en 1978

66. A. Michel, \& La théologie latine [sur la Trinité] du vir au $\mathrm{xx}^{-}$siècle , Dictionnaire de théologie catholique XV/2, Paris, 1950, col. 1709-1730.

67. Maric-Dominique Chenu, La théologie au douzième siècle, Paris, 1957, p. 115 (Études de philosophie médiévale, dir. Étienne Gilson, 45), parle de son " prestige absolu, son crédit religieux (qui) vaut équivalemment de son crédit philosophique .

68. G. Gaillard, × La pénétration clunisienne en Espagne pendant la première moitié du Nir siècle ", dans Études d'art roman, Paris, 1972, p. 84-92.

69. Ricardo del Arco, op. cit. (n. 3), p. 398 ; Angel Canellas Lopez, Angel San Vicente, op. cit. (n. 50), p. 159-160.

70. D'après Antonio Duran Gudiol qui a publié toutes les inscriptions de la province. 
que dans l'Historia Turpini Roland propose à Ferragut diverses images pour lui faire comprendre ce qu'est la Trinité ; la cithare, l'amande, le soleil, et enfin la roue qui a un moyeu, des rayons et une circonférence, et qui n'est cependant qu'une seule roue ${ }^{71}$. Serafín Moralejo qui rapporte cette proposition estime qu'elle ne peut sans doute pas s'appliquer à Jaca, parce que le moyeu y manque dans ce qui pourrait être une roue ${ }^{i 2}$. Dulce Ocón Alonso étudiant a la problématique du chrisme trinitaire " avance un sermon du saint évêque de Tolède, Ildefonse, qui compare la Trinité au soleil : " dans le soleil y a la roue, l'éclat et la chaleur. Dans la roue vois le Père, dans l'éclat le Fils, dans la chaleur l'Esprit. $n^{73}$ Elle note que le chrisme de Jaca serait le premier exemple du chrisme pyrénéen qui ajoute le $S$ au $X P$ du chrisme des premiers siècles, et suggère qu'on aurait rajouté le $S$ pour signifier le Saint Esprit ${ }^{\text {i4 }}$. L'explication de l'inscription du chrisme de Jaca par le mot pax, figure de la Trinité, rend caduque l'hypothèse de l'adjonction du $S$ pour donner un sens trinitaire au chrisme. Le $S$ du chrisme pyrénéen doit être simplement la finale du XPS, abréviation des plus fréquentes à l'époque romane, en un temps où l'on ne comprend plus bien les lettres grecques. On peut d'ailleurs se demander comment on aurait plus de trois cents tympans à chrisme « trinitaire " dans la région pyrénéenne alors que les tympans à caractère trinitaire sont rarissimes.

Il faut finalement se demander ce que pouvait comprendre de ce tympan celui qui entrait dans la cathédrale de Jaca. Très probablement pas le sens voulu par l'auteur du programme, à partir de la lecture d'Atton de Verceil, un sens si subtil qu'aucun des nombreux chercheurs qui ont travaillé sur ces textes ne l'avait percé. L'auteur même du programme comprend-il le sens du chrisme, on peut se le demander dans la mesure où il détourne complètement la signification christologique normale du chrisme en faisant des lettres grecques des lettres latines. Le visiteur devait repérer le " sceau chrétien " que donnait à l'église ce chrisme qu'il voyait par-

71. Op. rit. (n. 40 , p. 203.

72. « La sculpture romane de la cathédrale de Jaca. État des questions o, art. cit. in. 1), p. 93, n. 51. L'auteur pense plutôt à une sorte d'orbis dont les rayons pourraicnt représenter la croix et les quatre parties du monde, tout le schéma étant rempli de rosaces astrales s.

73. "Problemática del crísmon trinitario ", Archivo español de arte, $n^{\circ} 223,1983$, p. 254 (P. I.., 96, c. 281 : in ipso /sole] tria considera : rotam scilicet, splendorem atque calorem. In rotam accipe Patrem, in splendorem Filium, in fervorem Spiritum Sonctum, Dans I'Ilistoria Tirpini 'n. 67; une des images est aussi le suleil : In sole tria sunt candor, splendor et calor, et tamen unus solus est. le sermon d'Ildefonse qui utilise aussi les images de la cithare et de la noix a dû servir de source au Liber Callixtinus.

74. Ibid., p. 2/2, 2/6 et 2/9. L'auteur traite aussi du tympan de Jaca dans sa thèse sur les Timpanos romainicos españoles : reinos de Aragoin . Navarra, I, Madrid, 1987, p. 242. 
tout autour de lui, et sans doute saisissait-il, à l'intérieur de la circonférence la croix tracée par le $P$ et le trait horizontal ajouté au chrisme. Le clerc plus savant devait comprendre le sens des lions, en s'aidant des bestiaires qui lui étaient familiers, et il pouvait commenter le sens de l'appel à la pénitence figurant dans les trois vers du bas du tympan. Mais il fallait être capable de lire le texte écrit autour du cercle du chrisme pour saisir qu'on y parlait de la Trinité, même si on ne percevait pas le sens du deuxième vers, et le rapprochement du mot pax avec les trois personnes de la Trinité. « Le plus important pour nous est la porte de l'église offrant un message : le tympan de Jaca est un incunable de cette nouvelle conception. Avec les inscriptions et l'iconographie de ce tympan le silence sublime du symbolisme traditionnel de la porte sacrée est remplacé par une dramatique homélie » faisait observer Willibald Sauerländer”. Jusqu'aux tympans gothiques, le plus généralement anépigraphes, tympans et façades vont délivrer des messages expliqués par des inscriptions. A nous d'essayer de les bien comprendre, sachant que, comme il est habituel, de tout temps, pour toute ceuvre, il y a, pour le spectateur, plusieurs niveaux de lecture, en fonction de sa sensibilité, de son attention, de sa culture et de la culture de son temps ${ }^{76}$.

75. Op. cit. in. 11 , p. $20-22$.

76. Robert Favreau, a Ie thème épigraphique de la porte „ Cahiers de Civilisation Médiésale XXIV, 1991, p. 267-279 (repris dans Ftudes d'épigraphie médiévale, p. 547-567). 


\section{ANNEXE}

Parallèle fait par Atton 1I, évêque de Verceil (924-vers 960), entre le mot pax et la Trinité.

a Patrologia latina, t. 134, c. 554-555, Expositio in Epistolam ad Ephesios.

Il semble qu'Atton ait écrit ce commentaire avant de devenir évêque de Verceil. Dans le passage en question Atton commente Éphésiens II, 14, ipse est enim pax nostra $S i$, dans le reste de son commentaire, il paraphrase les commentaires sur la lettre aux Éphésiens de Jérôme et de Claude de Turin (Suzanne F. Wemple, Atto of Vercelli..., p. 25.26), il est original dans sa comparaison entre pax et Trinité. Le passage avant et le passage après sont copiés presque littéralement de Jérôme (Patrologia latina, t. 25, c. 472-473).

Haec [pax] igitur tribus scribitur litteris, nec pluralem recipit numerum. Estima ergo Patrem dici p, alpha Filium nuncupari, quia sicut a primum est elementum, ita Christus principium dicitur: nam cum esset interrogatus, dicit se esse principium [Jean VIII, 25]. Verum hæc syllaba longa est, et prima. Quod longa est, æternitatem, non temporalitatem Christi significat: quod syllaba, quia in Patre est Filius, et Pater in Filio, et hoc unum est : quod vero prima est; quia Filius secundus non est : ut illud : Ego sum a et $\omega$, primus et novissimus $[\Lambda$ poc. 1,8$]$ : novissimus, quia nasci et mori voluit : $\chi$ autem tertia est ad finem littera, quæ significat $S$ piritum sanctum non ad finem tendere, sed in superna majestate semper praecellere. Ideo Apostolus dicit: Qua sursum sunt sapite [Coloss. III, 2]. Et idcirco monemur, ut quotidie sursum cor habeamus... Ut igitur fiat pax, ad p conjungitur a vocalis, ne p muta remaneat, quia Pater voci, et verbo suo semper adnectitur: sed ut pax sit, aditur $\mathbf{x}$, quae duplex ponitur pro duabus consonantibus littera, quia participatur Patri, et Filio, et Spiritui sancto. Distant a se appellationibus hax litteræe et personis. Quare? Quia illud p, hoc a, istud $\mathbf{x}$ dicitur. $P$ autem littera est, sed substantialiter : similiter a littera substantialiter, et $\mathbf{x}$ littera substantialiter. Ita Pater, Deus naturaliter, etc. Sicut pax tribus litteris scribitur, ita Deus Trinitas 
est ; et sicut pax, ita Deus singularem obtinet numerum Deitatis. In hac igitur copulatione litterarum, trium divisio non admittitur, ut pax impleatur : si enim vel unum subtraxeris, nec Trinitas, nec pax erit.

Rufin, évêque d'Assise, au début de son De bono pacis libri duo écrit en 1181-1182, définit le mot Pax comme exprimant le mystère de la Trinité.

a - Patrologia latina, t. 150, c. 1594-1595.

Le Père Yves Congar a montré, dans son article sur «Maître Rufin et son De bono pacis " (Revue des sciences philosophiques et théologiques, t. XLI, 1957, p. 428-444) que l'auteur du De bono pacis était le maitre Rufin commentateur de Gratien en 1157-1159, devenu évêque d'Assise en 1179 .

De bono pacis integram volentibus habere notitiam, ordinarium est ut primo de rei nomine, postea de re nominis doctrina proponatur. Nomen ergo hujus boni Pax dicitur, quod utique vocabulum æternæ Trinitatis egregium exprimit sacramentum. Hoc enim nomen declinatur quidem, sed in pluralitatem non deflectitur, discretam illam in Deo subimaginans unitatem. In qua scilicet ct discretio personarum est, et unius ejusdemque naturæ simplicitas observatur. Sicut igitur hoc nomen in tribus permanet litteris et alia littera est $P$, alia $A$, alia $X$, quae sunt una dictio non resoluta in pluralem numerum (non enim paces dicimus), sic et deitas in tribus personis consistit, ut sit alia persona Pater, alia Filius, et alia Spiritus sanctus. Qui tres non plures essentiæ, sed una essentia, unus deus sunt.

P, quia prima littera est, Patrem innuit ; A, quæ media Filium ; $\mathbf{X}$, quæ in ultimis ponitur, Spiritum sanctum quamproprie repræsentat. Porro duplici ratione $\mathbf{P}$ Patris personam insinuat. Prima ea est, quod hujus nomen, scilicet pater ab ea littera incipit. Secunda, quia cum duæ litteræ sint, quæ labia compressa discopulant, videlicet $P$ et $B$, dum impressius [f. compressius] ad formandum $P$ quam B labia ipsa stringuntur, expressiori sono se ad effusionem ejusdem vocis aperiunt. Sicut ergo in ista littera magis panduntur labia, ut vox ipsa formata proferatur : sic omnia, quæ prius in abditis divinæ dispositionis quasi sonus voci, corde conceptus, latuerant, formari et velut aperiri per creationis opificium inchoarunt. Cujus creationis auctoritatem Scriptura Patri 
potius consuevit ascribere, cum ab ipso facta omnia commemorat. Unde Apostolus ad Corinthios ait: "Unus Deus Pater, ex quo omnia. "

Item A similiter ex duplici causa Filium credatur ostendere. Primum, quia vocalis est, id est per se sonans, et Filius per se visus et cognitus est. Secundo, quia hæc littera ante omnia litterarum elementa prima est : et Filius primogenitus ante omnem creaturam. Sicut autem ante omnem creaturam est, ita et post omnem creaturam. Est enim $A$ et $\Omega$ primus et novissimus, unde Primogenitus et Unigenitus appellatur: Primogenitus ante quem nullus exstitit: Unigenitus, post quem nullus erit.

Ut autem conceptio hujus nominis impleta permaneat, tertia littera, scilicet $X$, duabus præcedentibus adtaxatur. Quæ personam Spiritus sancti per geminum modum præfigurat, videlicet per naturam vocis et ordinem dispositionis. Per vocis naturam, quia duplex consonans est, in quo merito Spiritum sanctum indicat propter duplicem, quæ in eo intelligitur, consonantiam charitatis : unam, per quam Patrem Filio: alteram, per quam creaturam conjungit Creatori. Est enim, ut doctor Augustinus divinissimus tradidit, est, inquam, Spiritus sanctus amor utrumque conjungens nosque subjungens per ordinem dispositionis, quomodo hæc littera tertia est a fine, hoc est antepenultima. Duæ enim tantum post istam in abecedario sequuntur $Y$ et $Z$. Harum ergo trium litterarum $X$ prima est, per quod illa mysterii forma concipitur, quod cum tres sint rationabilium spirituum species, videlicet incircumscriptibilis, circumscriptibilis, sed non circumclusibilis, circumscriptibilis, pariter et circumclusibilis. De his tribus Spiritus sanctus primus est, scilicet incircumscriptibilis spiritus; circumscriptibilis, sed non circumclusibilis, spiritus angelicus; circumscriptibilis pariter et circumclusibilis, humanus. Y, quod ab uno plantario incipiens, in duos postea ramos deducitur, angelicus spiritus est, bonus utique creatus; qui postea in aversione quorumdam et aliorum conversione divisus apparuit. $\mathrm{Z}$, quod obflexiori charactere scribitur, spiritum notat hominis, quem cum Deus, juxta Ecclesiastem, simplicem rectumque condiderit, ipse postmodum anfractuosis et infinitis tentavit se quæstionibus immiscere.

MM. Robert-Henri Bautier, Jean Irigoin, Jacques Monfrin, André CaQuot, Jean Leclant et Pierre Toubert interviennent après cette communication. 
M. Michel Mollat du JouRdin présente les observations suivantes :

"La communication que nous venons d'entendre est une illustration et une justification de l'ceuvre entreprise par M. Favreau pour le recensement des inscriptions médiévales dont il avait entretenu notre Compagnie en 1994. Elle montre que l'épigraphie est, en soi, unc discipline originale et qu'elle suppose une érudition sans limites.

L'étude qui vient de nous être présentée offre une signification particulièrement importante. Elle repose en effet sur une exégèse rigoureuse fondée sur la connaissance et l'analyse des concordances dans les textes sacrés et profanes, telles qu'en a donné l'exemple le Cardinal de Lubac dans les quatre volumes de son Exégèse médiévale; il faut ainsi connaître la symbolique et l'allégorie qui enrichirent la liturgie pour comprendre les motifs et les formules de l'oeuvre considérée. La signification des uns et des autres a, par leur datation, une portée historique, car outre des parentés des animaux représentés avec les Bestiaires l'affirmation de la filiation trinitaire se situe, ici, au coeur de la querelle entre Rome et Byzance sur la question du "Filioque procedit", et la proclamation du dogme trinitaire se place face à l'lslam, encore proche de Jaca.

A noter enfin l'intention pédagogique disposant, par le procédé de l'image et de la formule, son affirmation à l'entrée du sanctuaire.

En conclusion, cette communication très solide répond parfaitement à la vocation de notre Compagnie destinée à l'étude des “inscriptions"."

\section{LIVRES OFFERTS}

M. Jacques MoNfrix a la parole pour deux hommages :

a J'ai l'honneur de déposer sur le bureau de l'Académic, de la part de son auteur, M"re Odette Bresson, ancien conservateur à la bibliothèque Sainte-Geneviève, le Catalogue du fonds hispanique ancien (1492-1808) de la bibliothèque Sainte-Geneviève de Paris. Préface d'Augustin Redondo, in- $8^{\circ}$, Paris, Presses de la Sorbonne Nouvelle, XVI-413 p. [Textes et Documents du 